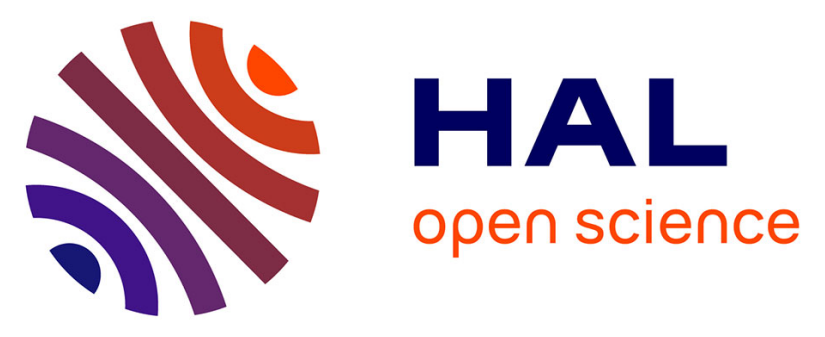

\title{
Preliminary characterization of SWOT hydrology error budget and global capabilities
}

Sylvain Biancamaria, Kostantinos M. Andreadis, Michael Durand, Elizabeth

A. Clark, Ernesto Rodriguez, Nelly Mognard, Doug Alsdorf, D. P.

Lettenmaier, Yannick Oudin

\section{To cite this version:}

Sylvain Biancamaria, Kostantinos M. Andreadis, Michael Durand, Elizabeth A. Clark, Ernesto Rodriguez, et al.. Preliminary characterization of SWOT hydrology error budget and global capabilities. IEEE Journal of Selected Topics in Applied Earth Observations and Remote Sensing, 2010, 3 (1), pp.6-19. 10.1109/JSTARS.2009.2034614 . hal-00575488

\section{HAL Id: hal-00575488 \\ https://hal.science/hal-00575488}

Submitted on 10 Mar 2011

HAL is a multi-disciplinary open access archive for the deposit and dissemination of scientific research documents, whether they are published or not. The documents may come from teaching and research institutions in France or abroad, or from public or private research centers.
L'archive ouverte pluridisciplinaire HAL, est destinée au dépôt et à la diffusion de documents scientifiques de niveau recherche, publiés ou non, émanant des établissements d'enseignement et de recherche français ou étrangers, des laboratoires publics ou privés. 
Preliminary characterization of SWOT hydrology error budget and global capabilities

S. Biancamaria ${ }^{1, *}$, K. M. Andreadis ${ }^{2}$, M. Durand ${ }^{3}$, E. A. Clark ${ }^{2}$, E. Rodriguez ${ }^{4}$, N.M. Mognard $^{1}$, D. E. Alsdorf ${ }^{3,5}$, D. P. Lettenmaier ${ }^{2}$, Y. Oudin ${ }^{1}$

${ }^{1}$ Université de Toulouse; UPS (OMP-PCA); LEGOS; 14 Av. Edouard Belin, F-31400 Toulouse, France.

${ }^{2}$ Department of Civil and Environmental Engineering, University of Washington, Seattle, Washington, WA 98195 USA.

${ }^{3}$ Byrd Polar Research Center, Ohio State University, Columbus, Ohio, OH 43210 USA.

${ }^{4}$ Jet Propulsion Laboratory, California Institute of Technology, Pasadena ,California, CA 91107 USA.

${ }^{5}$ School of Earth Sciences, Ohio State University, Columbus, Ohio, OH 43210 USA.

* Corresponding author. Mailing address: LEGOS, 14 av. Edouard Belin, F-31400 Toulouse, FRANCE. Tel.: $+33 \quad 5 \quad 61 \quad 33 \quad 29 \quad 30$; fax: $\begin{array}{llllllll}+33 & 5 & 61 & 25 & 32 & 05 & \text { Email: }\end{array}$ sylvain.biancamaria@legos.obs-mip.fr (S. Biancamaria)

(c) 2010 IEEE. Personal use of this material is permitted. Permission from IEEE must be obtained for all other users, including reprinting/ republishing this material for advertising or promotional purposes, creating new collective works for resale or redistribution to servers or lists, or reuse of any copyrighted components of this work in other works. 
Abstract:

River discharge and lake water storage are critical elements of land surface hydrology, but are poorly observed globally. The Surface Water and Ocean Topography (SWOT) satellite mission will provide high-resolution measurements of water surface elevations with global coverage. Feasibility studies have been undertaken to help define the orbit inclination and repeat period. Preliminary error budgets have been computed for estimating instantaneous and monthly river discharge from SWOT measurements (errors are assumed uncorrelated).

Errors on monthly discharge due to SWOT temporal sampling were estimated using gauges and their observation times for two SWOT orbits with different inclinations $\left(78^{\circ}\right.$ and $74^{\circ}$ ). These errors have then been extrapolated to rivers globally. The $78^{\circ}$ and $74^{\circ}$ orbital inclinations allow a good sampling frequency, avoid tidal aliasing and cover almost all the continental surface. For a 22 day repeat orbit, a single point at $72^{\circ} \mathrm{N}$ is sampled 11 and 16 times during one repeat period for the $78^{\circ}$ and $74^{\circ}$ inclination orbit, respectively. Errors in instantaneous discharge are below $25 \%$ for rivers wider than $50 \mathrm{~m}$ (48\% of all rivers). Errors in monthly discharge are below $20 \%$ for rivers with drainage areas larger than $7000 \mathrm{~km}^{2}$ (34\% of all rivers).

A rough estimate of global lake storage change has been computed. Currently available satellite nadir altimetry data can only monitor $15 \%$ of the global lake volume variation, whereas from $50 \%$ to more than $65 \%$ of this variation will be observed by SWOT, thus providing a significant increase in our knowledge of lake hydrology.

Keywords: surface water; SWOT mission; river discharge; lake storage change; error. 


\section{Introduction}

Surface and atmospheric water represents $0.4 \%$ of the world's freshwater and $0.01 \%$ of the total water on earth, respectively. Freshwater lakes and reservoirs account for $74.5 \%$ of surface water; $1.8 \%$ resides in rivers; and the remainder is found in wetlands, soil, plants and animals [1]. Rivers and lakes are a key component of the continental hydrological cycle and are societally important. Between 1996 and 2005, about 80\% of all natural disasters were of meteorological or hydrological origin [2]. Since 1960, a significant rise of water-related extreme events (such as floods and windstorms) has occurred [2]. These events dramatically affect human societies; between 2000 and 2004, more than 1.5 billion people were affected by 1,942 water-related disasters. During the last decade, economic losses due to such disasters have been estimated at $\$ 446$ billion [2]. These extreme events are very challenging to predict.

Surface freshwater measurements are limited mostly to in situ networks of gauges that record water surface elevations at fixed points along river channels. The spatial distribution of gauges around the world is far from homogenous, especially in developing nations [2]. Gauge networks are implemented at the national level, and data availability depends on national policy. Measurement accuracy is highly dependent on the method used and the state of the river itself (gauge measurement accuracies decrease significantly during flood events and gauges can be affected by external factors). Finally, when and where gauge time series are available, they suffer from gaps in record, differences in processing and quality control [3].

Globally, the spatial and temporal distribution of water stored on the land surface and moving through river channels is known only crudely. Water movement in wetlands and across floodplains throughout the world is essentially unmeasured, significantly limiting our understanding of flood processes. Satellite data can be used to complement in-situ networks [4]. The height of water in rivers and lakes can be measured from nadir altimeters (ERS-1/2, 
JASON-1/2, TOPEX/Poseidon), and water masks can be derived from optical data (Landsat, MERIS, MODIS, SPOT) and SAR (Synthetic Aperture Radar) data. The main limitations of existing satellite datasets are their temporal revisit periods (10 to 30 days for altimeters) and their spatial resolutions (for nadir altimeters, rivers must be wider than $1 \mathrm{~km}$ and their coverage has large gaps).

In the near future, new satellite missions will be launched to measure different components of the hydrological cycle: snow pack (Cold Regions Hydrology High-resolution Observatory, CoRe-H2O mission and Deformation Ecosystem Structure and Dynamics of Ice, DESDynI mission), soil moisture (Soil Moisture Active-Passive, SMAP mission and Soil Moisture and Ocean Salinity, SMOS mission), gravity field and large-scale water movement (Gravity Recovery and Climate Experiment II, GRACE-II mission) and surface water (Surface Water and Ocean Topography, SWOT mission). These missions will greatly increase our knowledge of continental hydrology. Wide swath altimetry measurements made by the SWOT satellite mission will provide the potential for high-resolution characterization of water surface elevations and will contribute to a fundamental understanding of the global water cycle by providing global measurements of terrestrial surface water storage changes and discharge, which are critical for present and future climate modelling. The SWOT mission ([4], [5]) benefits from the strong heritage of the Shuttle Radar Topography Mission (SRTM, [6]), which occurred in February 2000 and allowed to compute the highest-resolution digital elevation model of the Earth, and the Wide Swath Ocean Altimeter (WSOA, [7]), which was initially planned to be implemented on JASON 2, before being cancelled.

The study presented here focuses on surface water hydrology that will be derived from the SWOT mission. It aims at developing a methodology to estimate the impact of different sources of error on the products that will be delivered by the SWOT mission. This satellite is not a gauge replacement mission and should be seen as powerful complement to in-situ 
networks. Previous studies ([4], [8]) have reviewed which hydrologic parameters can be measured with available satellite data and associated accuracy; this paper presents quantitative error estimates associated with the SWOT satellite mission. Different errors will affect SWOT data and the derived discharge: errors due to the satellite itself (instrument noise, roll angle error, phase error, error due to the orbit, to the spatial and temporal resolution, etc.), due to media delay error (ionosphere and wet troposphere errors) and due to ancillary data to estimate discharge (river bathymetry, etc.). The study presented here focuses only on few of them: error on the measured water elevation (assumed to be equal to a $10 \mathrm{~cm}$ error as requested in the science requirements, with no systematic bias, which results from different source of errors like instrumental noise, media delay, etc.) and due to the temporal sampling. Moreover, for simplicity and better understanding of their impact, these two types of errors are considered separately, even if in reality they will occur at the same time and impact each other.

\section{The SWOT mission}

\subsection{Presentation of the mission}

The SWOT mission will provide high-resolution measurements of water surface elevations over the ocean and continental surface water bodies. The main satellite payload is the Ka-band Radar Interferometer (KaRIN), a wide swath radar interferometer. Two antennas separated by a $10 \mathrm{~m}$ boom will observe two ground swaths of $60 \mathrm{~km}$ on each side of the nadir separated by $20 \mathrm{~km}$ (Figure 1). The distance between the two swaths will be partially covered by the measurements from a nadir altimeter. The intrinsic pixel resolution will vary from 60 $\mathrm{m}$ (near range) to $10 \mathrm{~m}$ (far range) across-track and will be at best around $5 \mathrm{~m}$ along-track 
(yet, this value will be a function of decorrelation time). The satellite is currently planned to be launched between 2013 and 2016 [9].

Over continents, the vertical accuracy for the water height measurements will be 10 $\mathrm{cm}$ for a $1 \mathrm{~km}^{2}$ pixel and the relative error on water body area estimated using SWOT water mask will be smaller than $20 \%$ of the total water body area (SWOT science requirements). Table 1 summarizes SWOT design parameters and science requirements for the hydrology mission. Classical altimeters like TOPEX/Poseidon or JASON 1 and 2 can only observe the water surface along their nadir, leading to $1 \mathrm{D}$ along track observations, which miss large portions of rivers, lakes and wetlands [4]. SWOT will provide 2D maps of water elevation with no gap during its nominal phase at an unprecedented horizontal resolution.

\subsection{SWOT Orbits}

The nominal lifetime of the mission is three years. The first three months will be a calibration-validation period (called 'fast sampling phase'), and the remaining time will correspond to the nominal phase of the mission. The nominal phase is a 22-day repeat orbit, which will yield a global coverage of the earth. The fast sampling phase corresponds to a 3day repeat orbit, allowing a more frequent revisit time but with incomplete global coverage (Figure 2). The altitude of both orbits is approximately $970 \mathrm{~km}$.

In this study, both $74^{\circ}$ and $78^{\circ}$ orbital inclinations have been considered. These two inclinations have been selected as they allow a good sampling frequency, avoid tidal aliasing and cover almost all the continental surface (except the most northern part of Greenland). The main difference between these two inclinations is the coverage at high latitude (Figure 2). The $74^{\circ}$ inclination yields more frequent revisits of the arctic basins; the $78^{\circ}$ inclination samples 
more of the high latitude oceans and ice sheets. This work analyzed the differences in the error budget for continental hydrology as a function of the orbit inclination and repeat period.

\section{Rivers}

Two primary sources of error associated with estimating discharge from SWOT measurements have been considered: 1) the impact of the SWOT measurement error on the instantaneous derived discharge product, and 2) the impact of the SWOT time sampling on the monthly discharge estimates (an hydrologic quantity frequently used for seasonal studies).

\subsection{Datasets}

To study the impact of SWOT measurement errors on estimates of instantaneous discharge, in-situ daily measurements of both discharge and water height measurements are required. A total of 74 gauges, in major river basins that represent a variety of hydroclimatological environments worldwide (Figure 3), were found to comply with the needs of the study (i.e. with both discharge and water height measurements). These datasets were obtained from the USGS (United States Geological Survey, [10]) for North America, the ANA (Agencia Nacional de Aguas, [11]), HyBAm (Hydro-geodynamique actuelle du Bassin Amazonien, [12]) for South America and the IWM (Institute of Water Modelling, Bangladesh, [13]) for gauges on different rivers in Bangladesh.

To analyze the impact of the SWOT temporal sampling on monthly discharge estimates, daily discharge time series on rivers with different hydrological regimes have been used. 216 in-situ daily discharge time series, with no gaps for at least two years, have been obtained from different institutions: USGS for North America gauges, ANA and HyBAm for 
gauges in the Amazon basin, ArcticRIMS (Arctic Rapid Integrated Monitoring System, [14]) for Arctic gauges and GRDC (Global Runoff Data Centre, [15]) for all the other gauges. Gauge locations are shown in Figure 4.

In-situ data used in these two studies have been measured on natural rivers but also on rivers which could be impacted by human activity (especially for mid-latitude rivers). At least no data on artificial canal have been used and all data have a seasonal cycle with some interanual variability.

In order to plot SWOT errors derived from gauges along a global river network (see section 3.2.2 for more details), the HYDRO1k dataset has been used (http://edc.usgs.gov/products/elevation/gtopo30/hydro/). It is a globally consistent hydrologic derivative dataset developed by the USGS, based on the world GTOPO30 DEM (30 arcsecond digital elevation model) and includes elevation data, compound topographic index, slope, flow direction, flow accumulation, drainage basins and streams.

\subsection{Instantaneous discharge error estimate}

\subsubsection{Methodology}

Discharge estimates are derived from SWOT's accurate measurements of the water surface elevation. The error associated with the instantaneous discharge estimates depends on the model used to derive discharge from water surface elevation. In this study, the relationship between water elevation measured by SWOT ( $\left.\mathrm{H}_{\mathrm{SWOT}}\right)$ and discharge $(\mathrm{Q})$ has been modelled by a power law (equation 1) with constant parameters (b, c and $\mathrm{H}_{0}$ ). Note that other more complex techniques have also been investigated by previous studies to convert water height to discharge, like assimilating SWOT measurements in hydraulic model ([16], [17]). 
$\mathrm{Q}=\mathrm{c} *\left(\mathrm{H}_{\mathrm{SWOT}}-\mathrm{H}_{0}\right)^{\mathrm{b}} \quad$ eq. 1

In equation $1, \mathrm{H}_{0}$ is the water elevation of the effective zero flow (close to the elevation of the river bed). This equation is frequently used to derive discharge from in-situ stage measurements in operational hydrology [18]. In this study, it has been assumed that the rating curve does not vary in time. This is a limitation of the methodology used, as the coefficients of the power law are dependent on the hydraulic flow regime (magnitude of flow from high to low), transition between gradually varied flow and rapidly varied flow, vegetation growth, change in channel shape, ... . Nevertheless, previous remote sensing studies have also successfully used rating curves to convert water elevation measured from nadir altimetry to estimate discharge, with error on the instantaneous discharge below 20\% ([19], [20], [21], [22]). These methods require using in-situ discharge measurements located near the satellite ground tracks to compute rating curves between in-situ discharge and satellite measured water height.

Our goal is to express the error on instantaneous discharge as a function of the error in the SWOT measurement. If $\mathrm{H}_{0}$ is assumed to be known, the error on the river depth $\mathrm{D}=$ $\mathrm{H}_{\mathrm{SWOT}}-\mathrm{H}_{0}$ is only due to the error on the SWOT measurement, $\mathrm{H}_{\mathrm{SWOT}}$. Assuming that the error on the discharge $(\mathrm{Q})$ is due to independent errors in D and in the model for $\mathrm{Q}$, the error on the discharge can be written as follows:

$$
\delta Q=\frac{\delta Q(D)}{\delta D} \delta D+\varepsilon_{Q} \quad \text { eq. } 2
$$

where $\varepsilon_{\mathrm{Q}}$ is the model error, assumed to be independent from the measurement error, $\delta \mathrm{D}$. In evaluating the predictive power of various physical quantities to estimate discharge, Dingman and Sharma [23] and Bjerklie et al. [24] showed that model errors are approximately multiplicative. Therefore, model error can be modelled as follow:

$\varepsilon_{Q}=\eta \cdot Q$

eq. 3

where $\eta$ is the fractional model error. From equation 1, the partial derivative is: 
From equations 2 to 4 , a simple prediction for the fractional discharge error is:

$$
\frac{\sigma_{Q}}{Q}=\sqrt{\eta^{2}+\left(b \frac{\sigma_{D}}{D}\right)^{2}} \quad \text { eq. } 5
$$

For the rest of this study, the error in river depth estimation $\left(\sigma_{D}\right)$ is assumed to be equal to the SWOT measurement error and is set to $10 \mathrm{~cm}$, the required precision of the KaRIN instrument. Equation 4 is obtained assuming that the coefficients of the rating curve are constants, which is a main limitation of the methodology used.

\subsubsection{Results}

As described in Appendix A, discharge and water height time series from the gauges presented in Figure 3 has allowed us to estimate the fractional model error $\eta$ as 0.2 and the $b$ coefficient as 2.0. Consequently SWOT discharge error $\left(\sigma_{\mathrm{Q}} / \mathrm{Q}\right)$ can be computed globally using equation 5 and the river characteristics derived from HYDRO1k. First, however, river depth $D$ must be estimated for each HYDRO1k river segment. This can be done by using drainage area estimates associated with HYDRO1k. Indeed, a power law relationship between drainage area and mean discharge has been derived using 19,589 GRDC gauges globally. Each continent was partitioned into 9 large-scale basins according to the Pfafstetter system [25] and different regression relationship was developed for each basin. Moreover, river depth for each river segment was then estimated from the mean discharge using a power law relationship from Moody and Troutman [26]: $\mathrm{D}=0.27 * \mathrm{Q}^{0.39}$ (the $95 \%$ confidence intervals for the exponent and the multiplicative coefficients are $[0.38 ; 0.40]$ and $[0.12 ; 0.63]$, respectively). The Moody and Troutman's regression was obtained with discharge data close to the mean annual value. Figure 5 shows a map of the estimated errors in instantaneous 
SWOT discharge estimates for South America (for discharge values around their annual mean). For most of the rivers globally, discharge error is between $20 \%$ (the minimum error, due to rating curve model used) and $30 \%$.

Based on the work presented here (applying equation 5 with the fractional model error $\eta$ equal to 0.2 and the $b$ coefficient equal to 2 ), it has been established that for rivers deeper than $0.9 \mathrm{~m}$, the error in the instantaneous discharge will be below $30 \%$. For rivers deeper than $1.3 \mathrm{~m}$, the error will be below $25 \%$ (see appendix A and especially figure A.3 for an estimation of the sensitivity to the b coefficient).

\subsection{Sampling issues}

\subsubsection{Methodology}

The number of SWOT revisits per 22 day repeat orbit will be a function of latitude, ranging from twice at the equator to more than ten times at high latitudes for the nominal phase of the mission. Thus, while SWOT measurements will not provide daily discharge estimates, they will be utilized to provide weekly, monthly, and seasonal discharge estimates. The accuracy of these estimates will depend on temporal sampling; for instance, monthly discharge estimates will likely be more accurate for a river with six revisits per 22 day repeat orbit than for a river with two revisits. For example, for a location where a river is sampled twice in the 22-day repeat cycle, if both overpasses occurred during flood stage, an overestimation of the monthly discharge based on these observations will occur. Likewise, in some cases, SWOT may completely miss some events, leading to an error in estimates of maximum or minimum monthly discharge. This study assesses these errors using daily in-situ measurements from 216 river gauges around the world (Figure 4). For simplicity and better 
understanding of the impact of temporal sampling error, it is assumed that SWOT measurements have already been converted to discharge data and error on the instantaneous estimation of discharge is not taken into account, even if in reality they will impact each other. This assumption is made because in-situ discharge time series are much more readily available than those of water height. Since the errors on the monthly discharge are expressed in percentage, the results should be fairly similar for water height. Moreover, error on estimating discharge from SWOT measurements is characterized in the previous section.

First, SWOT observation times were determined for each of the 216 gauges in the dataset. Then, monthly discharge was estimated from both the entire time series of daily measurements (defined as the 'true' monthly discharge, $\mathrm{Qm}_{\mathrm{d}}$ ) as well as from the discharge

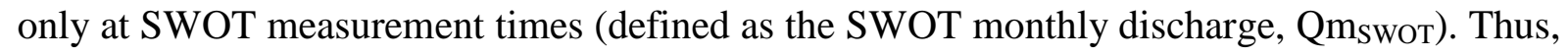
the error due to SWOT time sampling is given by equation 6 .

$$
\frac{\sigma_{t}}{Q}=\frac{\operatorname{std}\left(Q m_{d}-Q m_{S W O T}\right)}{\operatorname{mean}\left(Q_{d}\right)} \quad \text { eq. } 6
$$

\subsubsection{General considerations in discharge sampling}

In the previous section, the daily discharge is assumed to be representative of the truth for computing monthly and seasonal discharge variability while many hydrologic events (like rain events) occur at sub-daily time scales. To investigate this issue, sub-daily discharge variability in readily-available datasets was characterized. Hourly discharge time series for 122 gauges on the Ohio River and its tributaries (in Ohio, West Virginia and Kentucky states) were obtained from the USGS [10] (the shortest time series has a 1 year length and the longest has an 18 years length). A Fourier transform was performed for each gauge and the integrated variance for frequencies above 1/1day was computed as a percentage of the integrated variance for the frequencies above 1/365day. The variance is the square of the Fourier 
transform norm and the integrated variance for frequencies above 1/Xday is the integral of the variance over all periods below $\mathrm{X}$ days. Figure 6.a shows the value of this variance for each gauge as a function of drainage area. The variance contained in periods shorter than one day increases when the drainage area decreases. This is intuitively consistent with the idea that smaller river basins are more sensitive to individual precipitation events.

The intrinsic SWOT pixel horizontal resolution varies from $10 \mathrm{~m}$ to $60 \mathrm{~m}$ across-track, so the minimum river width seen by SWOT will be around $50 \mathrm{~m}$. The variance included in the periods below one day as a function of the mean river width at each gauge location is shown in Figure 6.b. The mean river width was derived from the drainage area by using a power law relationship, estimated for river width (derived from Landsat images) and drainage area at USGS gauge locations for the whole Ohio basin. The relationship used to calculate width is given by: Width $=1.62 \mathrm{Area}^{0.48}\left(\mathrm{r}^{2}=0.96\right)$. Of the 122 gauges used, only 20 have a river width above $50 \mathrm{~m}$, for which the variance included in periods below one day is uniformly less than 1 $\%$ (Table 2). The variance included in the periods shorter than 3 days, 5 days, 10 days and 20 days was also computed (Table 2). These results strongly suggest that daily data can be used as "truth" for rivers wider than 50m. A 5-day temporal sampling should be adequate to study river discharge, at least for the Ohio and for rivers wider than $50 \mathrm{~m}$, as periods greater than 5 days include $94 \%$ of the variance.

To investigate this last result, the methodology described in section 3.1 (with daily discharge as truth) has been applied to a 5-day, 10-day and 20-day sub-sampling (which are regular samplings, unlike the SWOT irregular samplings). The mean error on the monthly estimate for the 216 gauges is equal to $6 \%, 14 \%$ and $26 \%$ for the 5-day, 10-day and 20-day sub-sampling, respectively. A 5-day sampling, for river width above 50m, gives fairly similar information compared to daily discharge. A 10-day sub-sampling leads to error on the 
monthly discharge around $15 \%$. A sampling above 10 days is too coarse to give an accurate estimate of the monthly discharge.

\subsubsection{SWOT temporal sampling}

The methodology described in section 3.3 .1 was applied to orbits with $74^{\circ}$ and $78^{\circ}$ inclinations for both the nominal and the fast sampling phase (i.e., for four orbits, total). Three different analyses were performed. Firstly, we calculated the number of times each gauge location was sampled, and characterized the relationship between the number of revisits and latitude. Secondly, we calculated monthly discharge error, and characterized these errors with the upstream contributing area of the river measured by the gauge. Thirdly, we summarized the monthly discharge error; the first two analyses were performed for the nominal phase only, and the third analysis was performed for both nominal and fast-sampling phase. All analyses were performed for both $74^{\circ}$ and $78^{\circ}$ inclination orbits. Figure 7 shows the histogram of the number of observations at the 216 gauges during one repeat period (i.e. 22 days) for the $78^{\circ}$ (Figure 7.a) and $74^{\circ}$ (Figure 7.c) inclinations. For both orbits, the median number of observations per 22 days is 3 . For the $78^{\circ}$ and $74^{\circ}$ orbital inclinations, respectively $35.3 \%$ and $33.8 \%$ of gauges are seen twice (the minimum number of observations) per repeat period. Figures 7.b and 7.d show the number of observations for each gauge as a function of latitude for the $78^{\circ}$ and $74^{\circ}$ inclinations, respectively. It is important to remember that the choice of inclination will primarily impact the high latitude gauges. SWOT sampling is not uniformly distributed in time during one repeat period. Depending on gauge location and orbital inclination, some gauges may be observed twice in two consecutive days and then not be sampled again for the next 10 days, therefore affecting the monthly discharge error. On average, the maximum time between two observations is 13 days for both orbits. 
Monthly discharge errors have been plotted as a function of the river drainage area for each gauge location (see Figure 8 for the nominal phase). For the nominal phase the mean monthly discharge error is $15 \%$ for the $78^{\circ}$ inclination orbit and $14 \%$ for the $74^{\circ}$ inclination orbit. From these plots, it is also possible to fit the mean and the maximum error on the monthly discharge as a function of drainage area (dashed blue and solid green curves, respectively, Figure 8). The fit to the maximum error was estimated by least-squares error minimization under the constraint that all data points be less than the polynomial prediction (except for Figure 8.b where a point has been excluded as it was an outlier and the maximum error fit would have been overestimated). It is thus possible to estimate the maximum and mean error along each river even if no in-situ measurements are available as long as the drainage area can be estimated. There is a clear relationship between monthly discharge error and contributing area. For $78^{\circ}$ and $74^{\circ}$ inclination orbits, rivers with drainage areas above $6900 \mathrm{~km}^{2}$ and $4300 \mathrm{~km}^{2}$, respectively, are expected to have monthly discharge error less than $20 \%$. For comparison, the drainage area of the Yellowstone river at Corwin Springs (Montana) is equal to $6783 \mathrm{~km}^{2}$ and the drainage area of the Hudson river at Hadley (New York) is equal to $4310 \mathrm{~km}^{2}$ [10]. An explanation of the clear decreasing relationship between error on the monthly discharge and drainage area is the flashiness of rivers with small drainage area. Indeed, these rivers are more sensitive to individual rain events and therefore have rapid short term changes in streamflow, which are not correctly sampled by SWOT (and sometimes not even seen by the satellite), leading to high error on the monthly discharge.

Table 3 presents the mean error on the monthly discharge for the $78^{\circ}$ and $74^{\circ}$ inclination orbits for both nominal and fast sampling phases for all gauges. The mean error is also shown separately for Arctic gauges (gauges above $50^{\circ} \mathrm{N}$ latitude), as the mean difference between the two inclinations is most important at high latitudes (Figure 7.b and 7.d). From 
Table 3, it is apparent that there are no significant differences between $78^{\circ}$ and $74^{\circ}$ inclinations. Thus, despite the greater number of high latitude observations, the $74^{\circ}$ inclination orbit does not improve error on the monthly discharge.

Using the HYDRO1k dataset to estimate the percentage of rivers seen during the fast sampling phase (the nominal phase does not have any gaps in its coverage), reveals that $39 \%$ and $41 \%$ of the world rivers are seen by the $78^{\circ}$ and $74^{\circ}$ inclination orbits, respectively.

In conclusion, the error on the monthly discharge estimate due to SWOT time sampling is expected to be around $15 \%$ for the nominal phase and $3 \%$ for the fast sampling phase. The study also shows there is almost no difference between $74^{\circ}$ and $78^{\circ}$ inclination orbits when computing the error on the monthly discharge, so for hydrologic studies, both inclinations are appropriate.

4. Lakes

Over lakes, SWOT will provide estimates of water volume variations and a time varying water mask. At present, there is a large uncertainty on the total number of lakes in the world [27], but SWOT measurements should greatly reduce this uncertainty. Storage change variations are a key term in the hydrologic water balance. In this section, an attempt is made to estimate the total annual storage change summed over all lakes on earth and the percentage of that change measureable by SWOT.

\subsection{Data used}

Three different datasets of yearly lake water level variation were used. The first one 
comes from TOPEX/Poseidon water elevation measurements over 12 African lakes from Mercier et al. [28]. The second dataset includes 94 lakes in North America measured in-situ by the USGS. The last dataset is the World Lake Database (WLD, http://www.ilec.or.jp/database/database.html) which provides annual water level fluctuation for 118 lakes, both regulated and unregulated.

\subsection{Methodology}

A simple approach is followed to estimate the total annual lake water volume change. For different bins of lake area between $0.001 \mathrm{~km}^{2}$ and $100,000 \mathrm{~km}^{2}$, the number of lakes whose area belongs to the different bins is estimated. Then, an estimate of the annual lake water level change for each bin is derived for the three datasets presented in section 4.1, and finally the water volume change for each bin is computed (equation 7).

Downing et al. [27] established a power-law relationship between number of lakes and lake area using 17,357 lakes, with areas from $10 \mathrm{~km}^{2}$ to $378,119 \mathrm{~km}^{2}$ (the latter represents the area of the Caspian Sea), from the Global Lakes and Wetlands Database (GLWD) of Lehner and Döll [29], which includes both natural lakes and manmade reservoirs. Using this relationship, they estimated that around 304 million lakes have an area above $0.001 \mathrm{~km}^{2}$. This relationship has been used to estimate the number of lakes in 71 lake area bins with a size above $0.001 \mathrm{~km}^{2}$ (Figure 9). The only issue is that for very large lake areas, if the bin is too small, there is no lake in the bin. Therefore, in this study, the last two bins were chosen to correspond to lakes with areas between $10,000 \mathrm{~km}^{2}$ and $100,000 \mathrm{~km}^{2}$ (10 lakes) and area between $100,000 \mathrm{~km}^{2}$ and $1,000,000 \mathrm{~km}^{2}$ (1 lake, the Caspian sea). Figure 9 shows the relationship between the number of lakes and lake areas for the 71 bins. For each bin a mean lake area has been computed and associated with the number of lakes. 
To estimate the amplitude of the annual water level change for each bin, the water level changes from USGS dataset were plotted versus drainage area (Figure 10.a) and from WLD data versus mean lake area (Figure 10.b). It was found that there is no correlation between the lake area or drainage area, and the lake amplitude. Indeed, it appears that the amplitude of the lake water level variation can be modelled as a log-normal distribution, as shown in Figure 11. Thus, it is assumed that the amplitude of water level variations in global lakes follows this log-normal distribution. The implication is that the total amount of annual storage change occurring in each of the bins in Figure 9 can be computed. This calculation could proceed in several ways; here it has been chosen to model the amplitude of the water level variations in each bin using a Monte Carlo method.

Then for each bin, the global storage change due to all the lakes in the bin can be computed as follow:

$d S_{i}=A_{i} \cdot \sum_{j=1}^{N_{i}} d H_{i}(j) \quad$ eq. 7

where $\mathrm{dS}_{\mathrm{i}}$ is the global storage change for bin $i, \mathrm{~A}_{\mathrm{i}}$ is the mean lake area, $\mathrm{N}_{\mathrm{i}}$ is the number of lakes in the bin and $\mathrm{dH}_{\mathrm{i}}$ is a vector of $\mathrm{N}_{\mathrm{i}}$ heights generated using Monte Carlo methods and the log-normal distribution shown in Figure 11. Equation 7 assumed that all lakes have a cylindrical shape.

\subsection{Results and discussion}

The methodology presented here predicts an annual volume variation for all lakes of around $9,000 \mathrm{~km}^{3}$. Due to the fact that there are many more small lakes than large lakes, $50 \%$ of the total water volume change is due to lakes with an area below $1 \mathrm{~km}^{2}$ (Figure 12).

Figure 12 shows an estimation of the percentage of total lake storage change that can be observed with current spaceborne remote sensing capabilities. Water storage change is 
currently measured from satellite by combining optical observations of water surface area and nadir altimeter measurements of water level [30]. These two datasets have different resolutions in space and time, and the altimetry data has a coarser resolution. Nadir altimeters cannot provide accurate measurement for lakes with an area below $100 \mathrm{~km}^{2}$ ([28], [30]). This means that, in theory, current satellite data cannot measure more than $30 \%$ of the total water storage change (see red dashed line on Figure 12). Alsdorf et al. [4] show that nadir altimeters with 10-day ( TOPEX/Poseidon, Jason series), 16-day (Terra series) and 35-day (ERS-1/2, ENVISAT series) repeat orbit periods and $98^{\circ}$ inclination orbits miss, respectively, $80 \%, 73 \%$ and $54 \%$ of the world lakes. Therefore, up to now, satellite data cannot measure more than $15 \%$ of the total lake storage change, assuming that current altimeters can at best see $50 \%$ of all lakes.

Figure 12 also shows the percentage of storage change that SWOT shall be able to estimate (in green, it is a mission requirement that SWOT shall sample all the lakes with an area greater then $1 \mathrm{~km}^{2}$ ) and the percentage SWOT could be able to observe (in blue, it is a mission goal to see all lakes with an area above $250 \times 250 \mathrm{~m}^{2}$, see below for more details).

Thus, SWOT should be able to monitor $51 \%$ of the global lake storage change (dashed green curve, Figure 12) if SWOT observes lakes with an area above $1 \mathrm{~km}^{2}$ and with $10 \mathrm{~cm}$ height accuracy (mission requirement).

SWOT should detect some lakes with areas less than $1 \mathrm{~km}^{2}$ (SWOT mission goals to sample lakes with an area larger than $250 \times 250 \mathrm{~m}^{2}$ ), even if the instrumental noise for these lakes is higher than for lakes with areas larger than $1 \mathrm{~km}^{2}$. Therefore, we assume that the satellite will be able to observe lakes with an area above 250x250 m (mission goal) with height accuracy dependent on lake area. The height accuracy for a 50x50 m pixel is $1 \mathrm{~m}$ and decreases when the lake area increases (aggregation of pixels decrease the measurement errors). However, it has been considered that the minimum height accuracy can never be 
lower than $10 \mathrm{~cm}$. When taking into account the science goal, it is found that SWOT should be able to monitor more than $68 \%$ of the global lake storage change.

A key assumption made in this study was that a log-normal distribution can accurately model annual lake height variations. To evaluate the sensitivity of these results to the parameters of the log-normal distribution, the storage change seen by SWOT was recomputed for different values of the log-normal mean and standard deviation (Figure 13).

In Figure 13, the top panel shows the global storage change measured by SWOT using the science goal (with a minimum lake size of $250 \times 250 \mathrm{~m}^{2}$ ) and the bottom plot using the science requirement (with a minimum lake size of $1 \mathrm{~km}^{2}$ ). On both plots, the black squares show the results obtained with the nominal log-normal parameters $(2.4 \mathrm{~m}$ mean and $2.1 \mathrm{~m}$ standard deviation). These results show that the storage change estimate is not very sensitive to the log-normal distribution parameters.

Another important source of error is the power law relationship between the number of lakes and their areas. Downing et al. [27] show that the number of lakes with large areas is pretty well known, whereas the number of small lakes (especially below $10 \mathrm{~km}^{2}$ ) is difficult to estimate. Yet, these small lakes contribute significantly to the total storage change and therefore error on their number can greatly impact global estimation of lake storage change.

Using GLWD, it is estimated that for the fast sampling phase $45 \%$ and $49 \%$ of all lake areas will be seen with an orbit inclination of $74^{\circ}$ and $78^{\circ}$, respectively.

\section{Conclusion and perspectives}

This study is a first attempt to estimate discharge errors derived from water height measured by the SWOT mission. The first source of error on derived discharge is the SWOT measurement error. From the mission science requirements, the instrument error on water 
height measurement will be $10 \mathrm{~cm}$. Assuming that the relationship between discharge and river depth can be modelled by a power law with constant coefficients (which is a significant limitation of the methodology used), the SWOT measurement error has been converted to error in instantaneous discharge estimates. Yet, for most rivers, discharge error is mainly due to model error, rather than measurement error, except for the smallest rivers. A second source of error is due to SWOT time sampling on monthly discharge estimates. Here again, the smaller the river, the flashier it is and therefore the higher the error is. From this work, these two types of error have been first estimated from in-situ measurements and have then been extrapolated globally. Yet, they have been considered separately for the moment, whereas in reality they will be combined. This issue will be addressed in future work, as well as the hypothesis of constant coefficients in the rating curve for the estimation of the first source of error.

The benefit of SWOT to improve our knowledge about lakes has also been investigated. A simple methodology has been used to estimate annual storage change over all lakes with an area above $0.001 \mathrm{~km}^{2}$. It has been estimated that using current satellite data, only $15 \%$ of the lake volume variation can be observed, whereas with SWOT from $50 \%$ to more than $65 \%$ of the global lake storage change will be observed. In the future, the study could be extended to artificial reservoirs using the ICOLD (International Commission On Large Dams) database.

The SWOT mission represents a step increase for continental hydrology. Further studies are needed to refine the SWOT error budget for discharge and storage change. In particular, the impact of water mask and bathymetry errors has not been addressed here and requires further investigation.

Acknowledgement 
The authors want to thank particularly all the institutions which have collected and given freely in-situ time series used in this paper, i.e. ANA, ArcticRIMS, HyBAm, IWM and USGS. In particular they are grateful to Dr. Stephane Calmant, IRD/LEGOS, for providing the ANA/HyBAm dataset and Dr. Faisal Hossain, Tennessee Tech University, for providing the IWM dataset.

The authors would like to acknowledge Guillaume Azema and Alain Lamy from CNES for providing SWOT orbit files.

One of the authors (S. Biancamaria) is supported by a CNES/Noveltis grant.

\section{Appendix A}

Estimating sensitivity of discharge error to parameter and model error when using a rating curve

The parameters of the rating curve $\left(\mathrm{b}, \mathrm{c}\right.$ and $\mathrm{H}_{0}$ in equation 1$)$ and the fractional model error $\eta$ can be computed from water elevation and discharge measured by in-situ gauges. The fractional discharge error due to the SWOT measurement error can be computed for the 74 gauges shown in Figure 3. Figure A.1 shows the estimated fractional model error $(\eta)$ versus the SWOT measurement error (b. $\left.\sigma_{\mathrm{D}} / \mathrm{D}\right)$ for all gauges. For most of them, the model error, which covers a wider range of values, outweighs the measurement error. The median, mean and maximum errors due to the measurement error are $4 \%, 6 \%$ and $24 \%$, respectively, whereas the median, mean and maximum model errors are 5\%,11\% and 47\%, respectively. Furthermore, the median, mean and maximum discharge errors $\left(\sigma_{\mathrm{Q}} / \mathrm{Q}\right)$ computed from equation 5 for the in-situ gauges are $9 \%, 13 \%$ and $49 \%$, respectively. 
It is difficult to estimate model errors from in-situ measurements, as the model errors can be under/overestimated in some cases, as illustrated in Figure A.2. The four plots in this figure show discharge versus water height measurements (blue dots) for four gauges and the fitted power law for these gauges (dashed red curve). Very often, discharge data are not measured directly but are derived from a power law applied to the water height measurements (Figure A.2.a). Therefore the model error is close to zero, which is, of course, unrealistic. For other gauges (Figure A.2.c), outliers in the measurements lead to erroneous estimation of the fitted rating curve, thus the model error is overestimated. Finally, data from some gauges are inconsistent (because of changes in the gauge baseline for example) or a single rating curve can not be applied, as in Figure A.2.d. However, for gauges with no obvious defect in the fitted rating curve, the model error is about $20 \%$ (Figure A.2.b). Thus, it can then be assumed that a fractional model error of $20 \%$ in equation 5 is a good estimate. This result is similar to previous studies ([23], [24]).

After computing and analyzing instantaneous discharge errors from individual gauges, these results were extrapolated to estimate instantaneous discharge errors globally, even where no in-situ data are available. In equation $5, \sigma_{\mathrm{D}}$ is known (equal to $10 \mathrm{~cm}$ ), from the previous results $\eta$ can be fixed at 0.20 , and D can be derived from the HYDRO1k network and in-situ data (see section 3.2). The power law exponent (coefficient $b$ in equation 1) needs to be studied further, especially to assess sensitivities in $\sigma_{\mathrm{Q}} / \mathrm{Q}$ to $b$. Figure A.3 shows discharge error versus river depth for three values of the $b$ coefficient. Discharge error is more sensitive to the $b$ coefficient when the river is shallow. For values of $b$ below 3 , this error is always below $30 \%$ for rivers deeper than $1.5 \mathrm{~m}$. Figure A.4 shows the histogram of the $b$ coefficient for 70 gauges (the other 4 gauges have $b$ coefficients above 10), and Table A.1 shows the median value of the $b$ coefficient for each river. 
The $b$ coefficient depends on the gauge location and varies along the same river (because of river topography, friction, etc.) and thus cannot be interpolated along the river. Nevertheless, from Figure A.4 and Table A.1, it appears that, for most rivers, the median value of the $b$ coefficient is around 2. Similarly, previous studies ([31], [32]) found a $b$ coefficient equal to 2 from theoretical consideration and few in-situ measurements. From hydraulic theory, Maidment et al. [18] write that "because natural channels are often parabolic in cross section, a value of about 2 for the exponent $[b]$ is appropriate where there is channel friction control".

Therefore, from in-situ measurements it can be inferred that the exponent of the rating curve is approximately equal to 2 and the fractional model error is around 0.2. 
References

[1] I. A. Shiklomanov and J. C. Rodda, World water Ressources at the beginning of the $21^{\text {st }}$ century. Cambridge University Press, 2003.

[2] UNESCO, "Water a shared responsibility", The United Nations World Water Development Report 2, 2006.

[3] K. D. Harvey and W. Grabs, "WMO Report of the GCOS/GTOS/HWRP expert meeting on hydrological data for global studies, Toronto, Canada, 18-20 November 2002”, Report GCOS 84, Report GTOS 32, WMO/TD - no. 1156, 2003.

[4] D. E. Alsdorf, E. Rodriguez and D. P. Lettenmaier, "Measuring surface water from space”, Reviews of Geophysics, vol. 45, no. 2, RG2002, doi:10.1029/2006RG000197, 2007.

[5] D. E. Alsdorf, L-L. Fu, N. Mognard, A. Cazenave, E. Rodriguez, D. Chelton and D. Lettenmaier, "Measuring the Global Oceans and Terrestrial Fresh Water from Space", EOS Transactions $A G U$, vol. 88, 253, 2007.

[6] T. G. Farr et al., "The Shuttle Radar Topography Mission”, Reviews of Geophysics, vol. 45, RG2004, doi:10.1029/2005RG000183, 2007.

[7] L.-L. Fu, and E. Rodriguez, "High-resolution measurement of ocean surface topography by radar interferometry for oceanographic and geophysical applications", in The State of the 
Planet: Frontiers and Challenges in Geophysics, Geophys. Monogr. Ser., vol. 150, edited by R. S. J. Sparks and C. J. Hawkesworth, pp. 209-224, AGU, Washington, D. C., 2004.

[8] R. W. Herschy, E. C. Barrett and J. N. Roozekraus, "The world's water resources - a major neglect. A study in remote sensing in hydrology and water management", ESA BR-40, 1988.

[9] National Research Council (NRC), "Earth science and applications from space: national imperatives for the next decade and beyond", Committee on earth science applications from space: a community assessment and strategy for the future, 2007.

[10] U.S. Geological Survey, National Water Information System (NWISWeb) data available on the World Wide Web, accessed between April 2008 and July 2009, at URL http://waterdata.usgs.gov/nwis/, 2001.

[11] Agencia Nacional de Aguas (ANA), http://www.ana.gov.br/

[12] Hydro-geodynamique actuelle du Bassin Amazonien (HyBAm), http://mafalda.teledetection.fr/hybam/whybam2/index.php

[13] Institute of Water Modelling, Bangladesh, http://www.iwmbd.org/

[14] Arctic Rapid Integrated Monitoring System (ArcticRIMS), http://rims.unh.edu

[15] The Global Runoff Data Centre, D - 56002 Koblenz, Germany (http://grdc.bafg.de). 
[16] K. M. Andreadis, E. A. Clark, D. P. Lettenmaier and D. E. Alsdorf, "Prospects for river discharge and depth estimation through assimilation of swath-altimetry into a raster-based hydrodynamics model”, Geophysical Research Letters, vol. 34, L10403, doi:10.1029/2007GL029721, 2007.

[17] M. Durand, K. M. Andreadis, D. E. Alsdorf, D. P. Lettenmaier, D. Moller and M. Wilson, "Estimation of bathymetric depth and slope from data assimilation of swath altimetry into a hydrodynamic model", Geophysical Research Letters, vol. 35, L20401, doi:10.1029/2008GL034150, 2008.

[18] D. R. Maidment, Handbook of Hydrology. USA: McGraw-Hill Inc., ch. 8, pp. 8.22, 1993.

[19] A. V. Kouraev, E. A. Zakharova, O. Samain, N. M. Mognard and A. Cazenave, “Ob' river discharge from TOPEX/Poseidon satellite altimetry (1992-2002)”, Remote Sensing of Environment, vol. 93, pp. 238-245, 2004.

[20] E. A. Zakharova, A. V. Kouraev, A. Cazenave and F. Seyler, "Amazon river discharge estimated from TOPEX/Poseidon altimetry", Comptes Rendus Geoscience, vol. 338, no. 3, pp. 188-196, 2005.

[21] M. T. Coe and C. M. Birkett, "Water Resources in the Lake Chad Basin: Prediction of river discharge and lake height from satellite radar altimetry", Water Resources Research, vol. 40, no. $10,2005$. 
[22] J. G. Leon, S. Calmant, F. Seyler, M.-P. Bonnet, M. Cauhope, F. Frappart, N. Filizola and P. Fraizy, "Rating curves and estimation of average water depth at the upper Negro River based on satellite altimeter data and modeled discharges", Journal of Hydrology, vol. 328, nos. 3-4, pp. 481-496, 2006.

[23] S. Dingman and K. Sharma, "Statistical development and validation of discharge equations for natural channels", Journal of Hydrology, vol. 199, pp. 13-35, 1997.

[24] D. Bjerklie, S. Dingman and C. Bolster, “ Comparison of constructive flow resistance equations based on the Manning and Chezy equations applied to natural rivers", Water Resources Research, vol. 41, no. W11502, doi:10.1029/2004WR003776, 2005.

[25] K.L. Verdin and J.P. Verdin, 1999, “A topological system for delineation and codification of the Earth's river basins”, Journal of Hydrology, vol. 218, nos. 1-2, pp. 1-12.

[26] J. A. Moody and B. M. Troutman, "Characterization of the spatial variability of channel morphology”, Earth Surface Processes Landforms, vol. 27, pp. 1251-1266, 2002.

[27] J. A. Downing, Y. T. Prairie, J. J. Cole, C. M. Duarte, L. J. Tranvik, R. G. Striegl, W. H. McDowell, P. Kortelainen, N. F. Caraco, J. M. Melack and J. J. Middelburg, "The global abundance and size distribution of lakes, ponds, and impoundments", Limnology and Oceanography, vol. 51, no. 5, pp. 2388-2397, 2006. 
[28] F. Mercier, A. Cazenave and C. Maheu, "Interannual lake level fluctuations (1993-1999) in Africa from Topex/Poseidon: connections with ocean-atmosphere interactions over the Indian Ocean”, Global and Planetary Changes, vol. 32, pp. 141-163, 2001.

[29] B. Lehner and P. Döll, "Development and validation of a global database of lakes, reservoirs and wetlands", Journal of Hydrology, vol. 296, pp. 1-22, 2004.

[30] J.-F. Crétaux and C. M. Birkett, "Lake studies from satellite radar altimetry", Comptes Rendus Geoscience, vol. 338, pp. 1098-1112, 2006.

[31] J. D. Fenton, "Rating curves: part2 - Representation and approximation", Proc. Conf. on Hydraulics in Civil Engineering, Hobart 28 -30 November, The Institution of Engineers, Australia, pp. 319-328, 2001.

[32] J. D. Fenton and R. J. Keller, "The calculation of streamflow from measurements of stage”, Technical Report 01/6, Cooperative Research Centre for Catchment Hydrology, Melbourne, 2001. 


\section{Table captions}

Table 1: SWOT design parameters and scientific requirements for the hydrology mission

Table 2: Mean, median and maximum variance contained in frequencies above 1/1day, 1/3day, 1/5day, 1/10day and 1/20day for the 20 stations on the Ohio river with a width (W) above $50 \mathrm{~m}$

Table 3: Mean error on the monthly discharge for the SWOT nominal and fast sampling phase, for all gauges and for Arctic gauges

Table A.1: Median value of the exponent of the power law between discharge and water height ( $b$ coefficient) for each river 


\section{Figure captions}

Figure 1: Conceptual view of the SWOT mission (courtesy of CNES)

Figure 2: Ground tracks of the SWOT fast sampling phase with a $140 \mathrm{~km}$ swath for a $74^{\circ}$ (a.) and a $78^{\circ}$ (b.) orbit inclination

Figure 3: Gauges, with daily discharge and stage time series, used in the study presented in section 3.2. The data come from USGS, ANA, HyBAM and IWM. 64 gauges are located in America (a.) and 10 in Bangladesh (b.)

Figure 4: Gauges, with daily discharge time series with no gaps, used in the study presented in section 3.3. The data come from USGS, GRDC, ArcticRIMS, ANA and HyBAM

Figure 5: Fractional discharge error $\left(\sigma_{\mathrm{Q}} / \mathrm{Q}\right)$ over South America

Figure 6: Variance contained in frequencies above 1/1day in \% of variance included in frequencies above 1/365day for 122 gauges on the Ohio river and its tributaries (discharge time series from USGS) versus drainage area (a.) and the river width (b.)

Figure 7: Number of gauges per number of observation and number of observation versus gauge latitude for 22 day repeat orbit at $78^{\circ}$ inclination (a. and b., respectively) and at $74^{\circ}$ inclination (c. and d.) 
Figure 8: Error on the monthly discharge estimate from 22 -day $78^{\circ}$ inclination orbit (a.) and 22-day $74^{\circ}$ inclination orbit (b.) versus river drainage area at gauge location

Figure 9: Number of lakes versus lake areas for the 71 bins

Figure 10: Figure 1. Amplitude of water level change from USGS (a.) and WLD (b.) vs drainage area

Figure 11: Cumulative Distribution Function (CDF) of the amplitude of the water level change

Figure 12: Cumulative global lake storage change (in \%)

Figure 13: Evolution of the SWOT global storage change estimates for different values of the log-normal parameters

Figure A.1: Fractional model error $(\eta)$ and measurement error (b. $\left.\sigma_{D} / D\right)$ from 74 gauges

Figure A.2: Rating curves (discharge versus stage) for 4 gauges: Brasileia (Acre river, Amazon basin, a.), Sylhet (Meghna river, b.), St-Paul (Mississippi river, c.) and Itaituba (Tapajós river, Amazon basin, d.)

Figure A.3: Fractional discharge error $\left(\sigma_{\mathrm{Q}} / \mathrm{Q}\right)$ versus river depth $(\mathrm{D})$ for $\eta=0.20$ and $\sigma_{\mathrm{D}}$ $=0.10 \mathrm{~m}$ 
Figure A.4: Histogram of the $b$ coefficient for 70 gauges (the other 4 have a $b$ coefficient above 10) 


\section{Tables}

Table 1:

\begin{tabular}{|c|c|c|}
\hline \multirow{4}{*}{ Orbit } & Altitude & $970 \mathrm{~km}$ \\
\hline & Inclination & $78^{\circ}\left(74^{\circ}\right)$ \\
\hline & Repeat period & 22 days (nominal phase) \\
\hline & Other & Non-sun synchronous \\
\hline \multirow{7}{*}{$\begin{array}{c}\text { KaRIN instrument } \\
\text { (SWOT main payload) }\end{array}$} & 1 swath coverage & $60 \mathrm{~km}$ \\
\hline & Total coverage & $140 \mathrm{~km}$ \\
\hline & Nadir gap & $20 \mathrm{~km}$ \\
\hline & Frequency & $35.6 \mathrm{GHz}$ \\
\hline & Mast length (baseline) & $10 \mathrm{~m}$ \\
\hline & Along-track resolution & $5 \mathrm{~m}$ \\
\hline & Across-track resolution & $10 \mathrm{~m}$ to $60 \mathrm{~m}$ \\
\hline \multirow{8}{*}{$\begin{array}{l}\text { Scientific requirements } \\
\text { on the SWOT mission }\end{array}$} & Minimum water body area seen & $250 \mathrm{~m}^{2}$ \\
\hline & Minimum river width seen & $100 \mathrm{~m}$ \\
\hline & Height accuracy & $<10 \mathrm{~cm}\left(\right.$ over $\left.1 \mathrm{~km}^{2}\right)$ \\
\hline & Slope accuracy & $1 \mathrm{~cm} / \mathrm{km}($ over 10 km) \\
\hline & Water mask area error & $\begin{array}{l}<20 \% \text { of the total water } \\
\text { body area }\end{array}$ \\
\hline & Minimum life time & 3 years \\
\hline & Data collect constraint & $\begin{array}{l}90 \% \text { of the orbit coverage } \\
\text { during } 90 \% \text { of the time }\end{array}$ \\
\hline & Calibration phase & $\begin{array}{l}3 \text { months on a 3-day repeat } \\
\text { orbit }\end{array}$ \\
\hline
\end{tabular}

Table 2:

\begin{tabular}{|c|c|c|c|}
\cline { 2 - 4 } \multicolumn{1}{c|}{} & \multicolumn{3}{c|}{ Variance $(\%$ of total variance for frequencies $>1 / 365$ day $)$} \\
\cline { 3 - 4 } & $\begin{array}{c}\text { Mean }(20 \text { gauges } \\
\mathrm{W}>50 \mathrm{~m})\end{array}$ & $\begin{array}{c}\text { Median }(20 \text { gauges } \\
\mathrm{W}>50 \mathrm{~m})\end{array}$ & $\begin{array}{c}\text { Maximum }(20 \\
\text { gauges } \mathrm{W}>50 \mathrm{~m})\end{array}$ \\
\hline Frequencies>1/1day & 0.3 & 0.2 & 1.1 \\
\hline Frequencies>1/3day & 2.3 & 2.0 & 6.2 \\
\hline Frequencies $>1 / 5$ day & 6.0 & 6.2 & 14.4 \\
\hline Frequencies>1/10day & 17.8 & 18.8 & 38.8 \\
\hline Frequencies>1/20day & 34.8 & 34.6 & 58.2 \\
\hline
\end{tabular}


Table 3:

\begin{tabular}{|c|c|c|c|}
\hline & \multicolumn{2}{|c|}{ Error on the monthly discharge } \\
\hline & & All (216 gauges) & Arctic (76 gauges) \\
\hline \multirow{2}{*}{$\begin{array}{l}\text { Nominal } \\
\text { phase }\end{array}$} & $78^{\circ}$ inclination & $15 \%$ & $18 \%$ \\
\hline & $74^{\circ}$ inclination & $14 \%$ & $16 \%$ \\
\hline \multirow{2}{*}{$\begin{array}{c}\text { Fast } \\
\text { sampling } \\
\text { phase }\end{array}$} & $78^{\circ}$ inclination & $3 \%$ & $4 \%$ \\
\hline & $74^{\circ}$ inclination & $3 \%$ & $4 \%$ \\
\hline
\end{tabular}

Table A.1:

\begin{tabular}{|c|c|}
\hline Rivers & Median(b) \\
\hline Amazon and tributaries & 2.0 \\
\hline $\begin{array}{c}\text { Brahmaputra, Ganges, } \\
\text { Meghna and Teesta }\end{array}$ & 3.2 \\
\hline Colorado & 2.5 \\
\hline Mississippi & 1.6 \\
\hline Missouri & 3.8 \\
\hline All rivers & 2.3 \\
\hline
\end{tabular}




\section{Figures}

Figure 1:

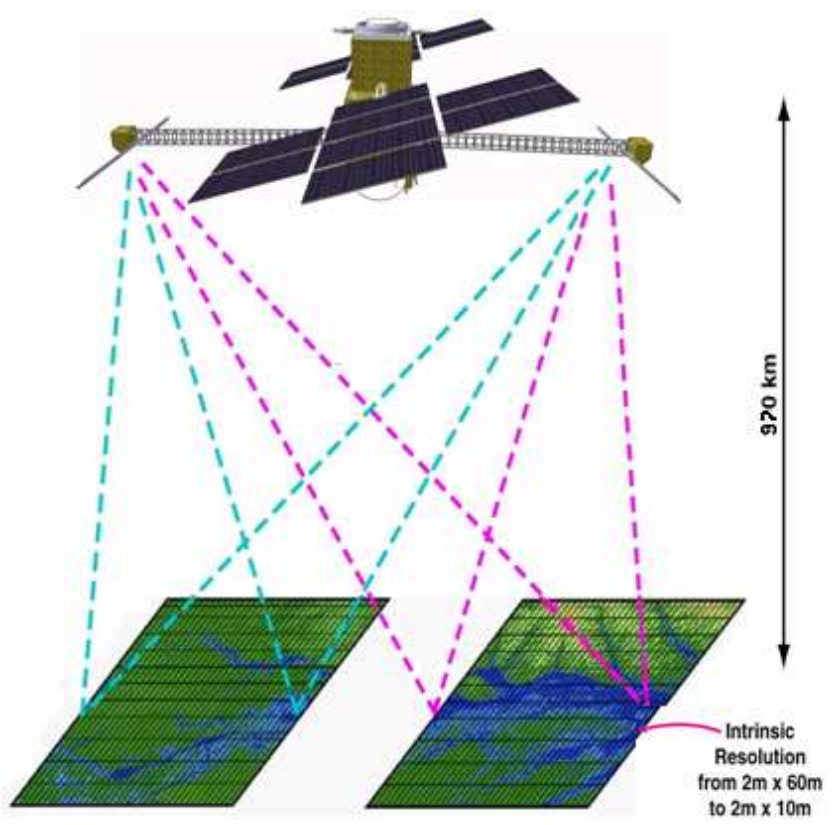

Figure 2:

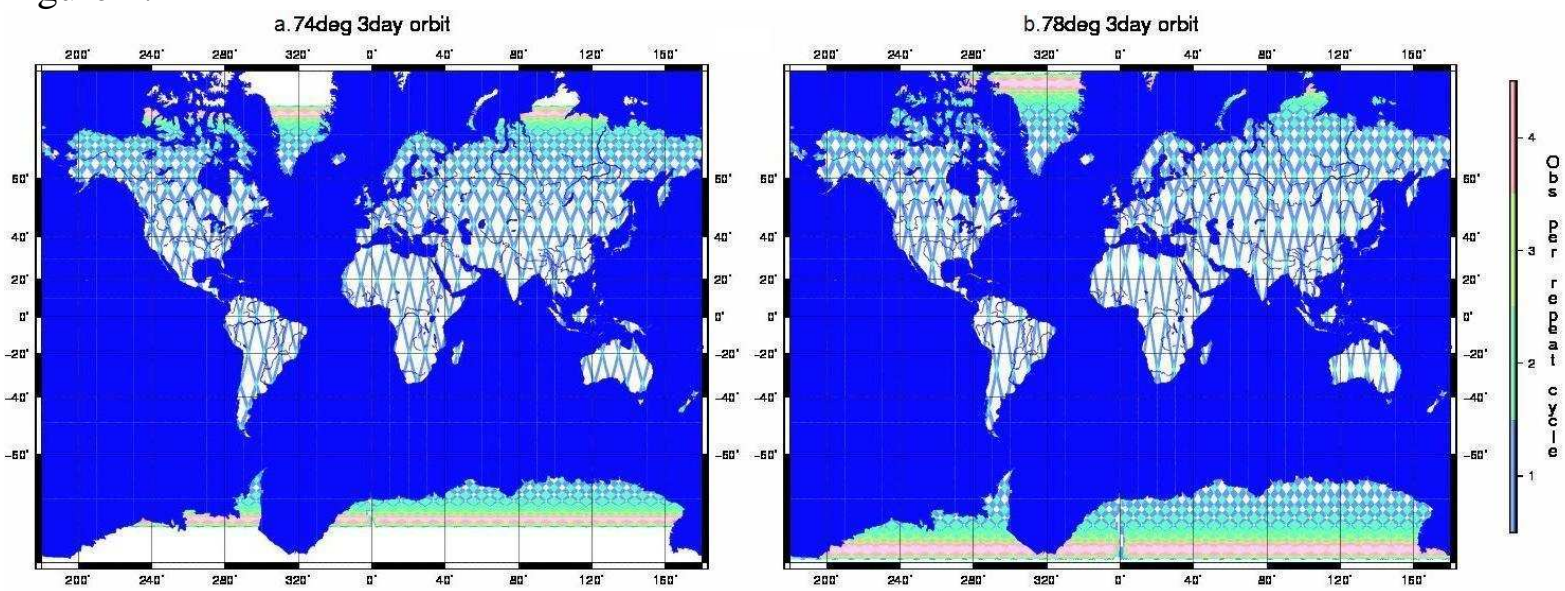


Figure 3:

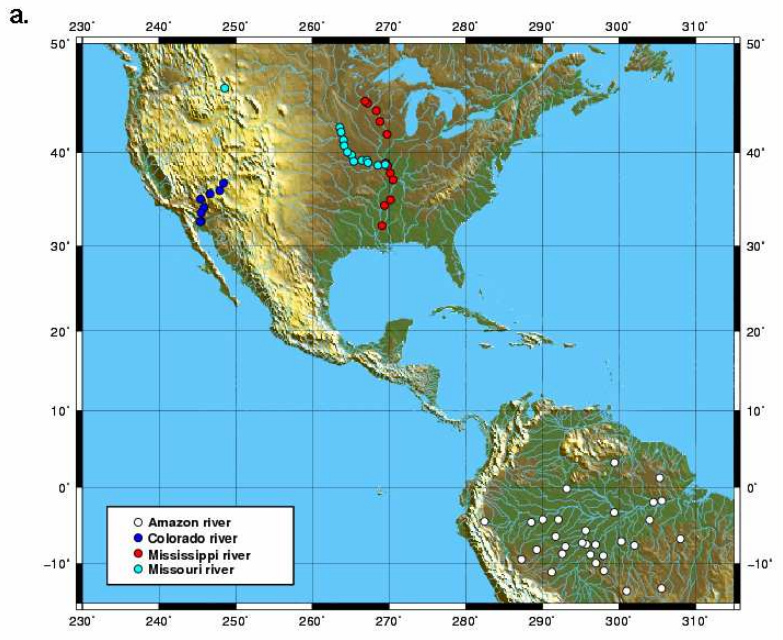

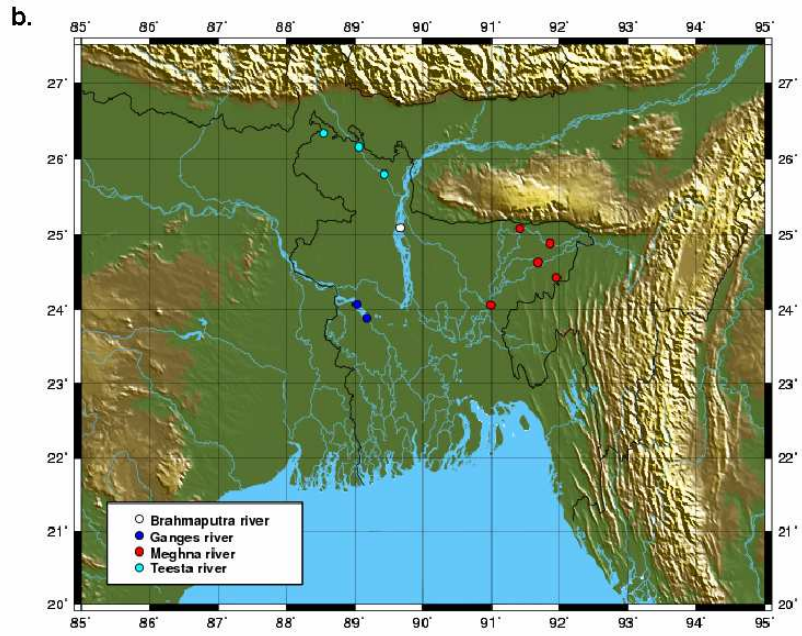

Figure 4:

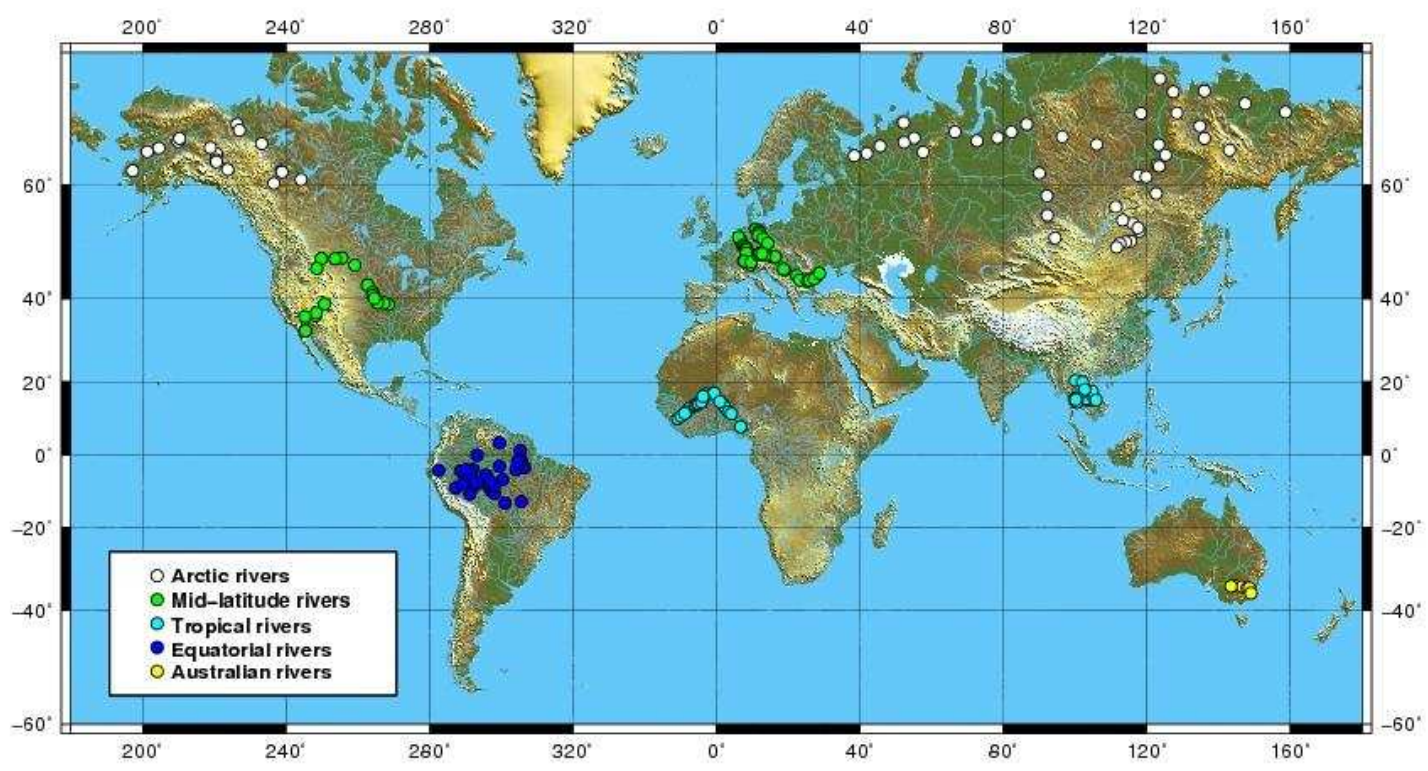


Figure 5:

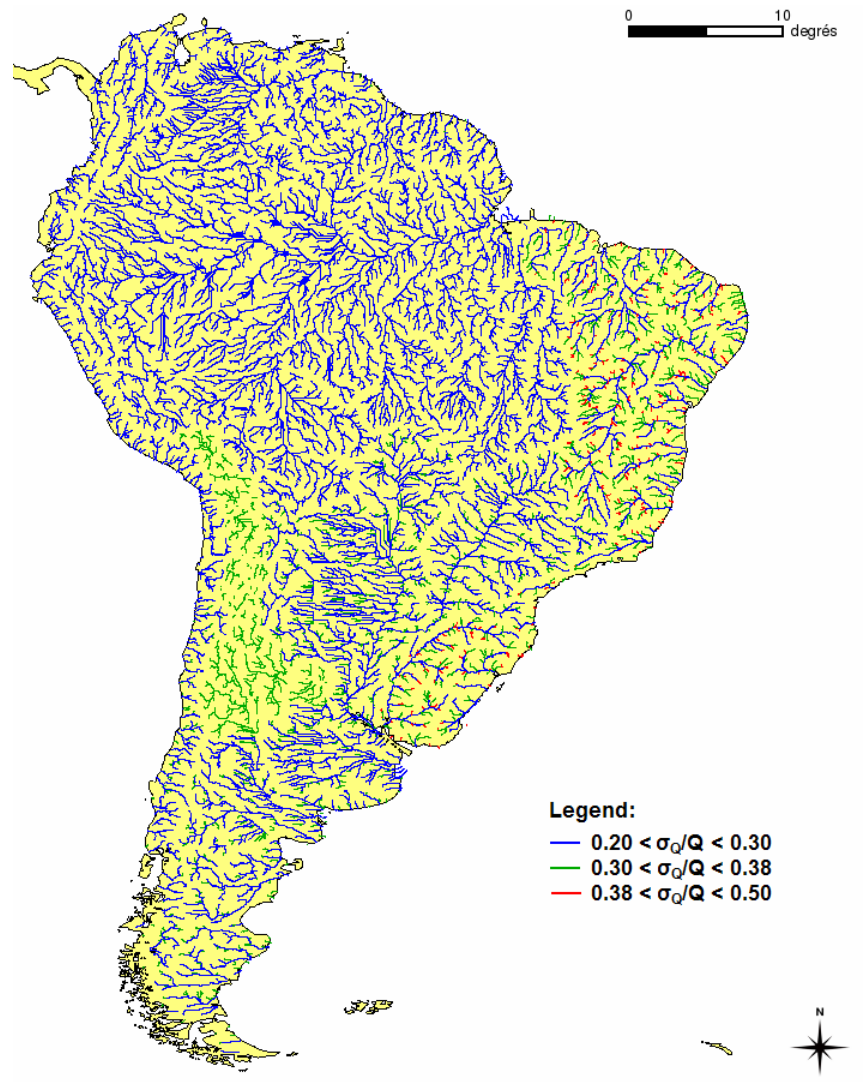

Figure 6:
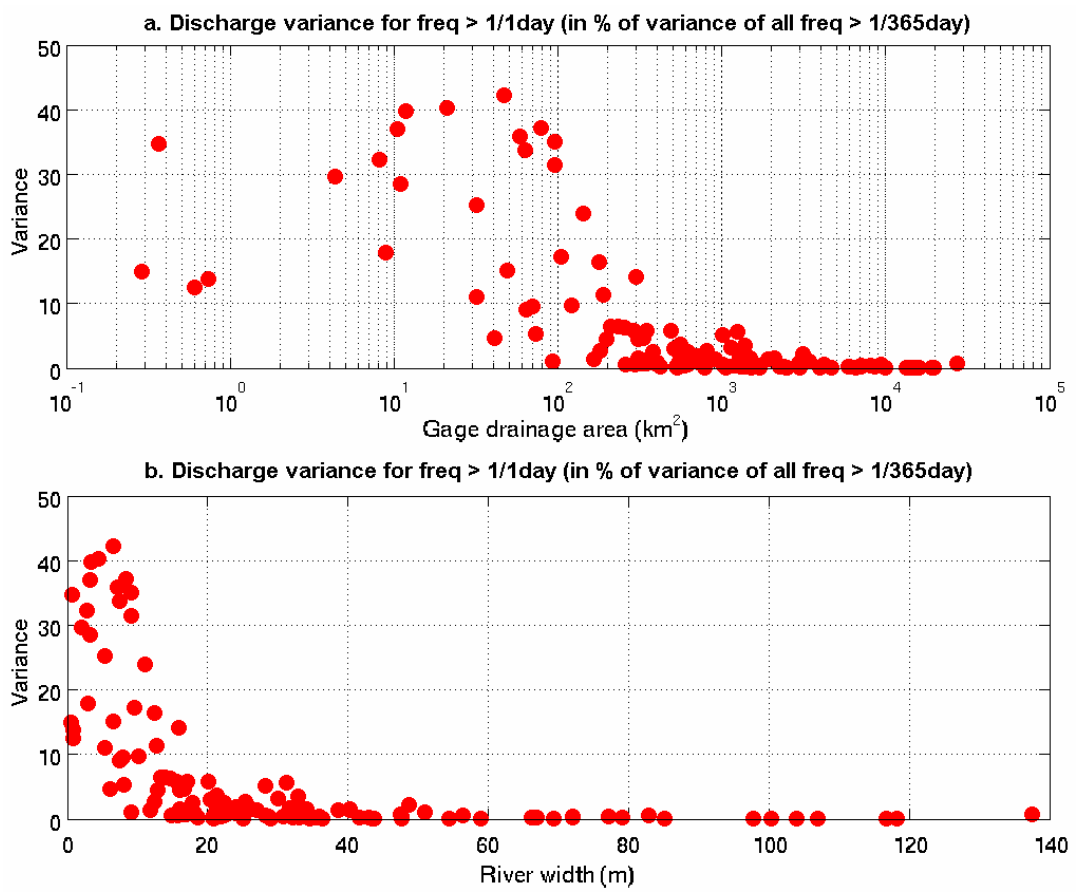
Figure 7:
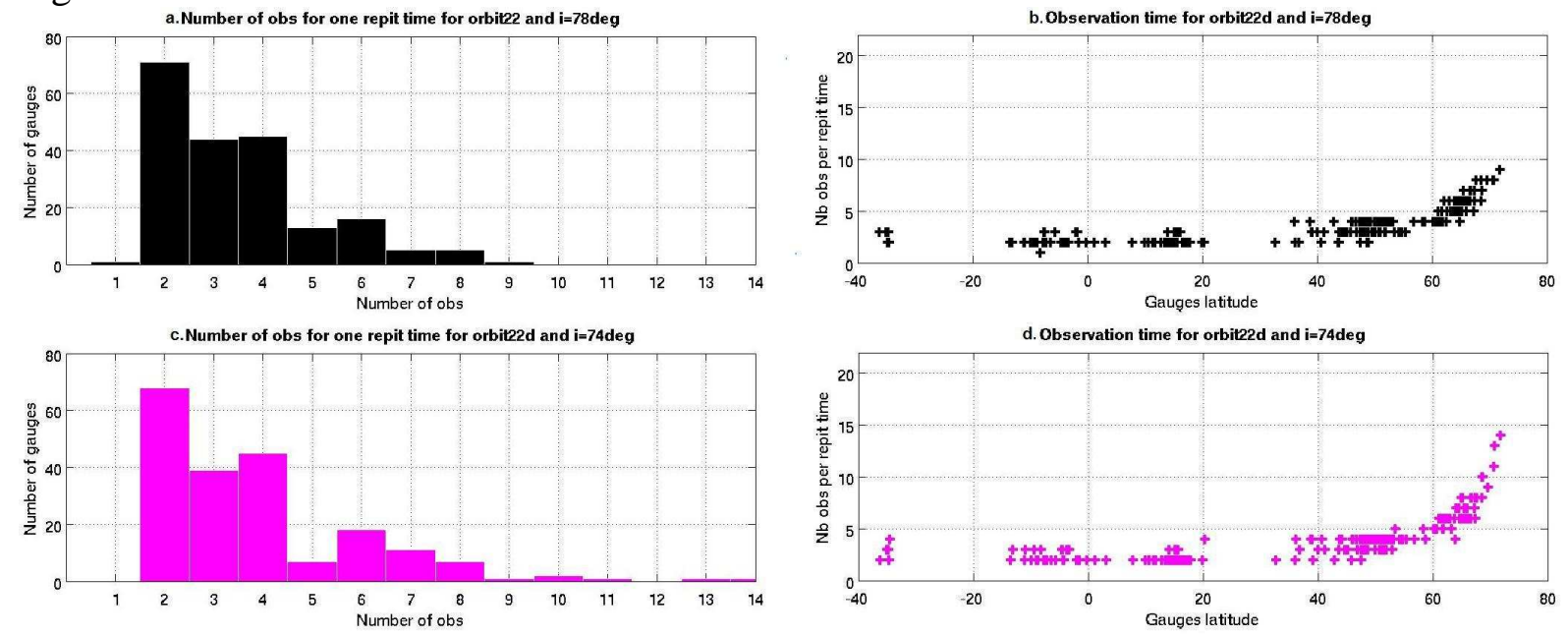

Figure 8:
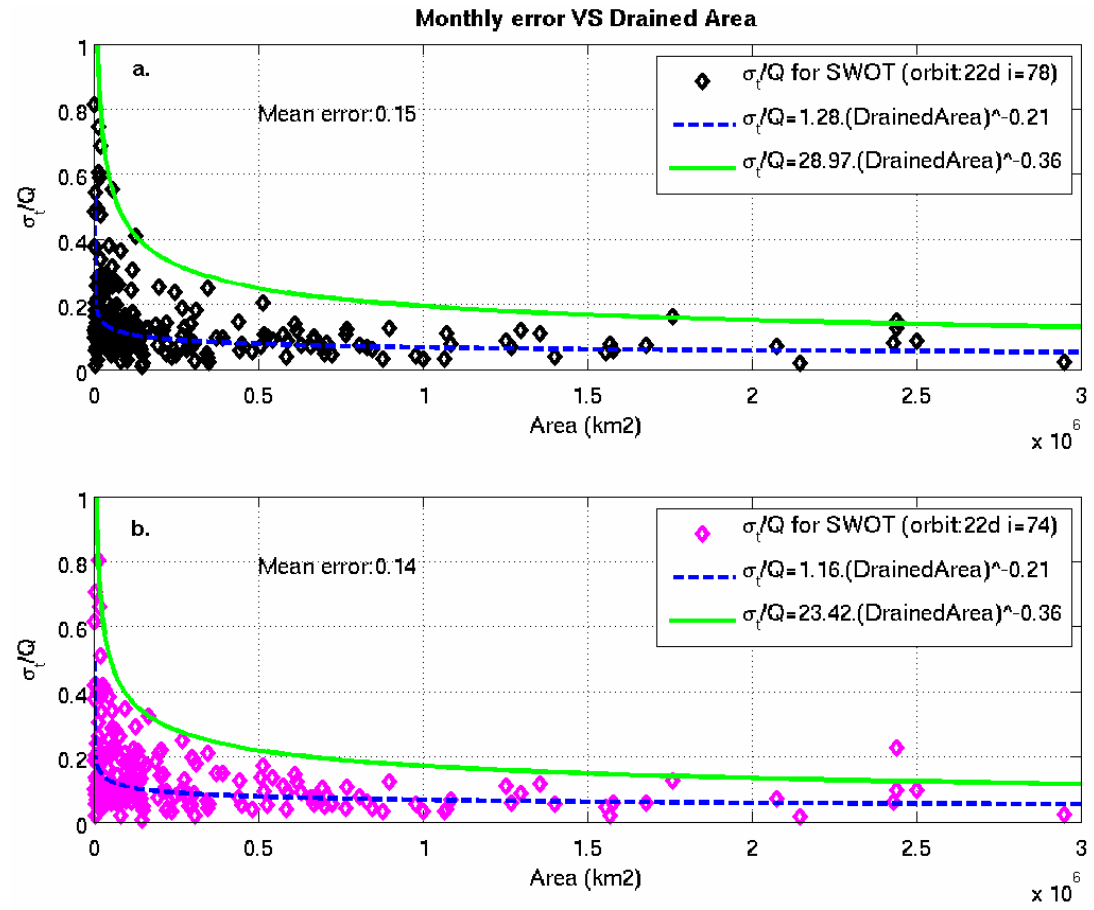
Figure 9:

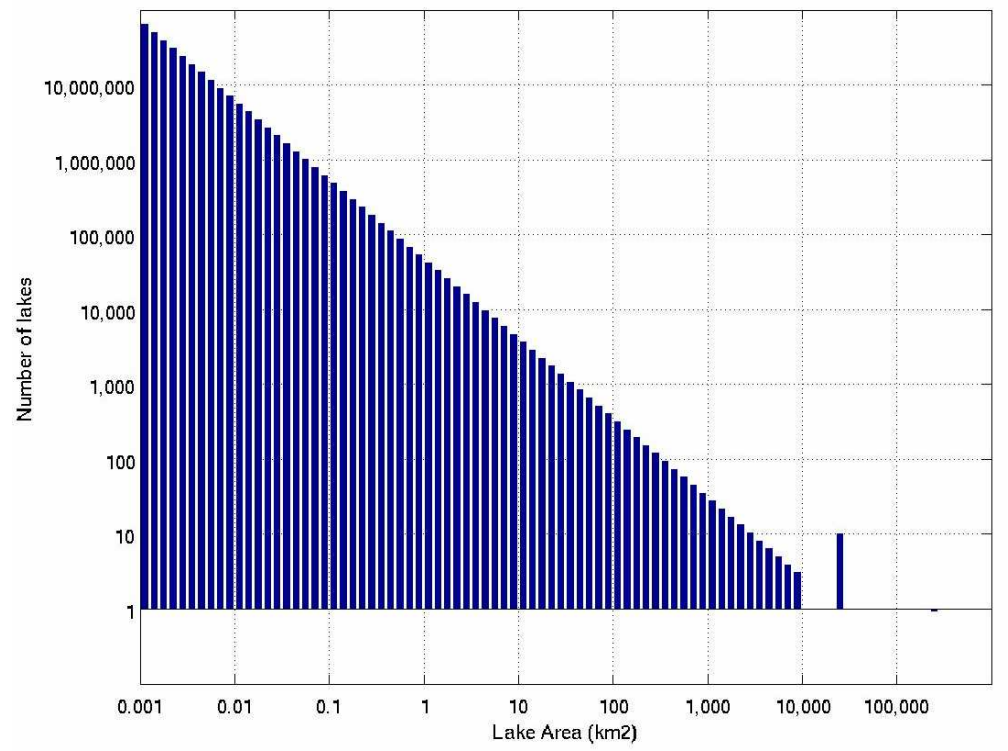

Figure 10:
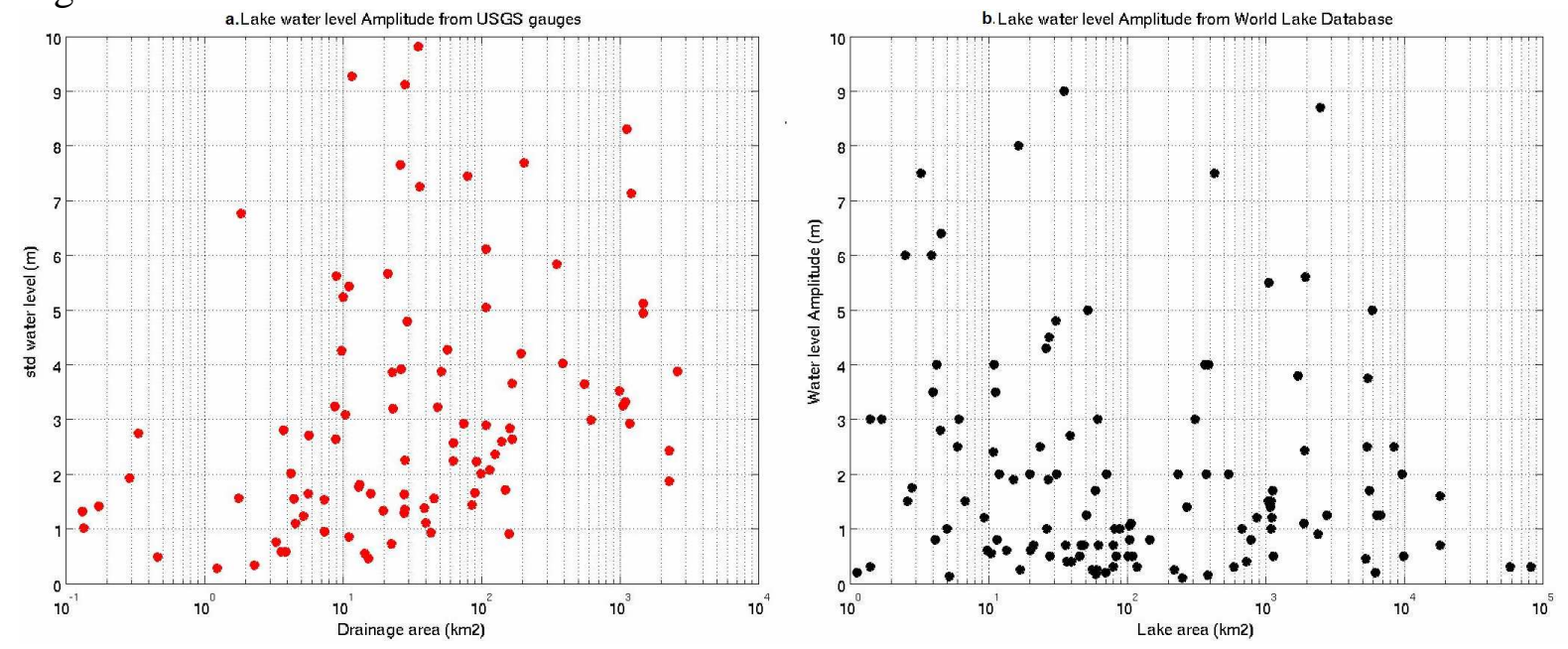
Figure 11:

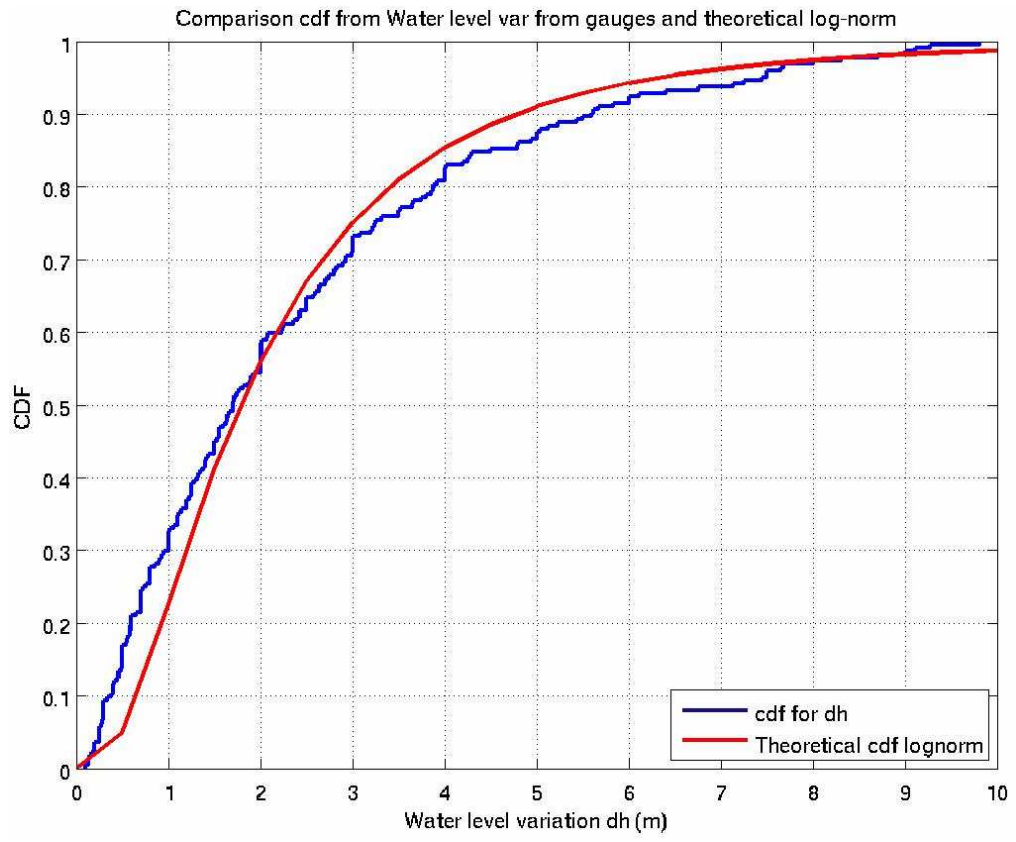

Figure 12:

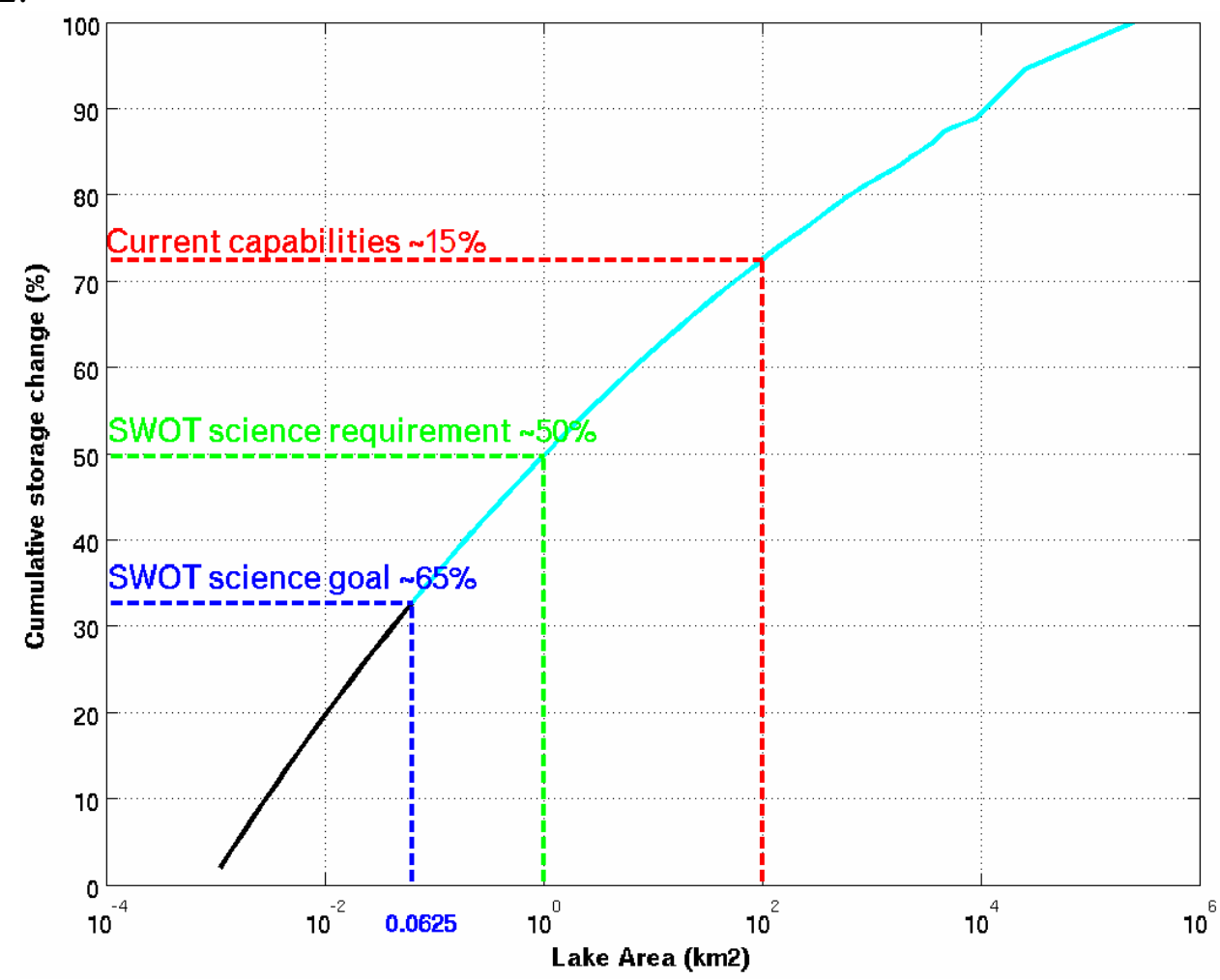


Figure 13:
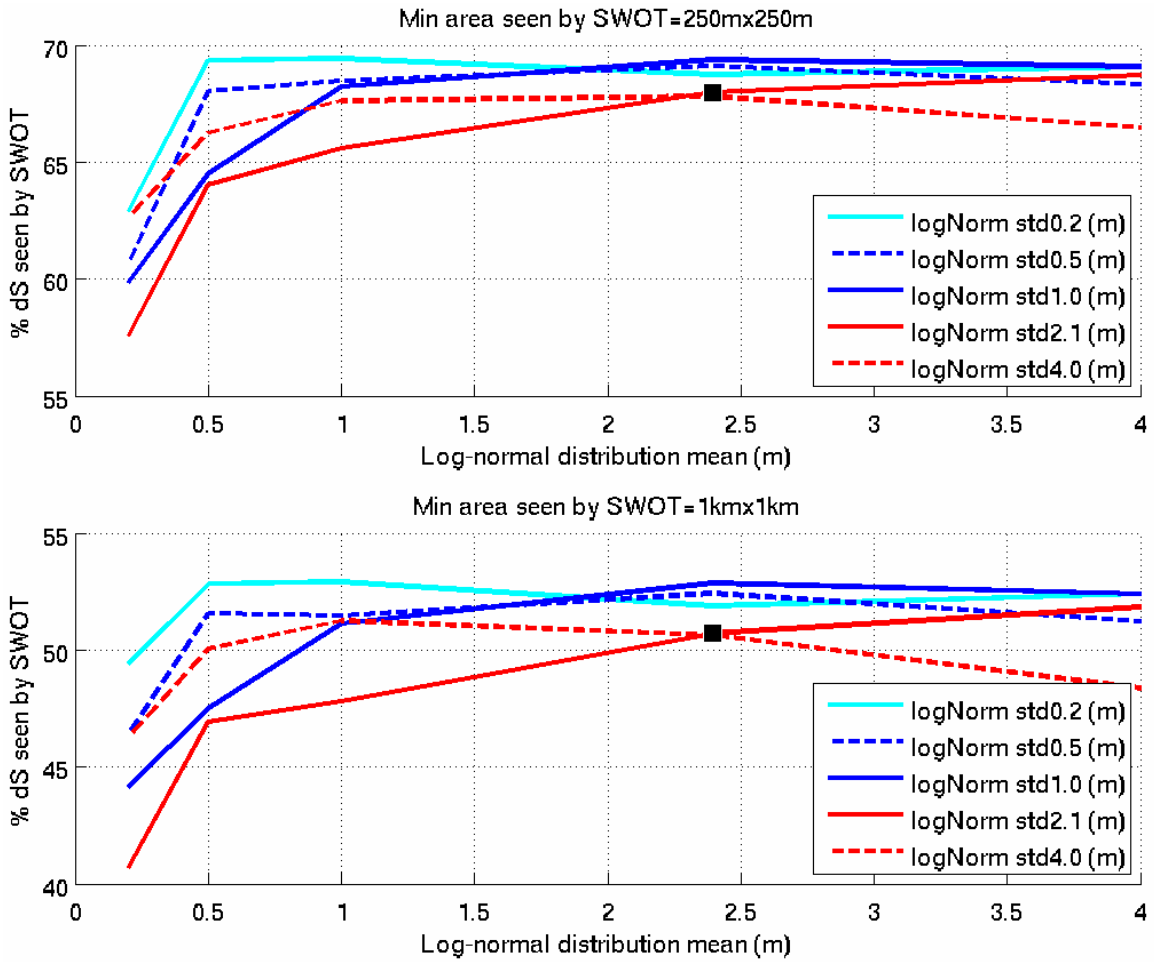

Figure A.1:

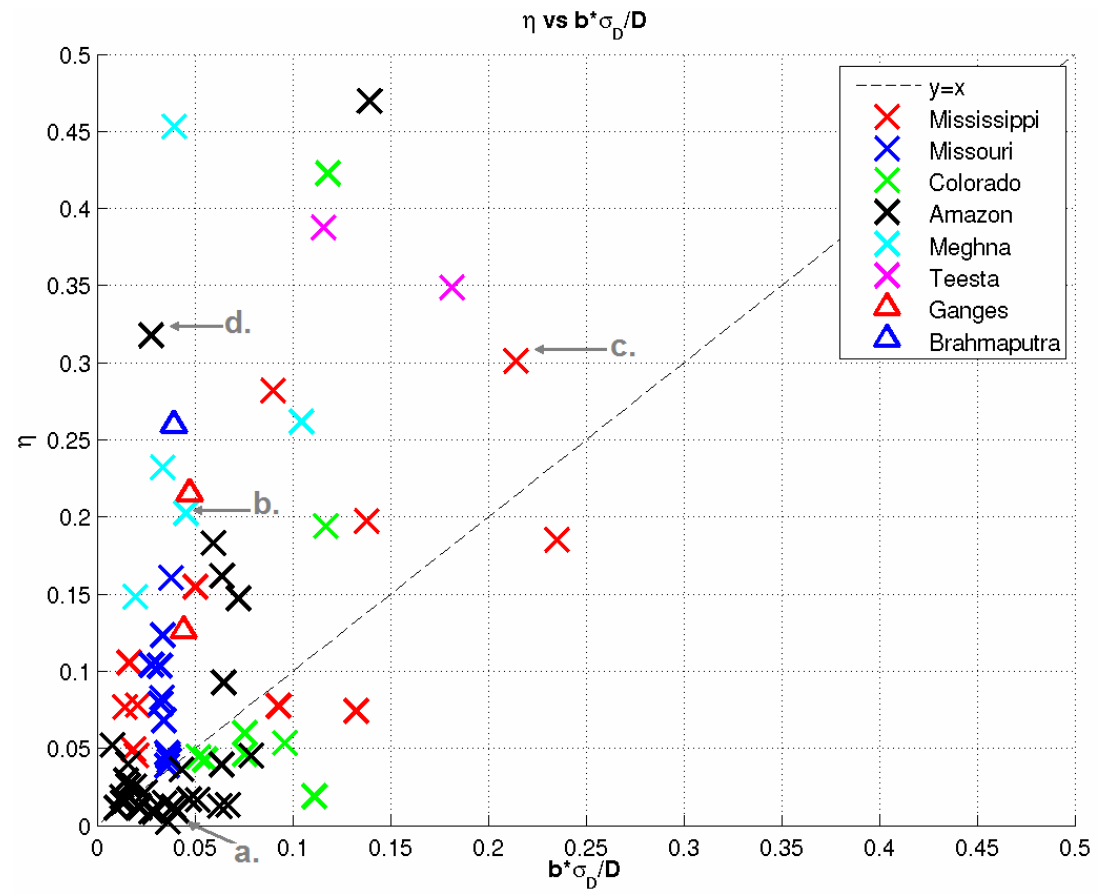


Figure A.2:
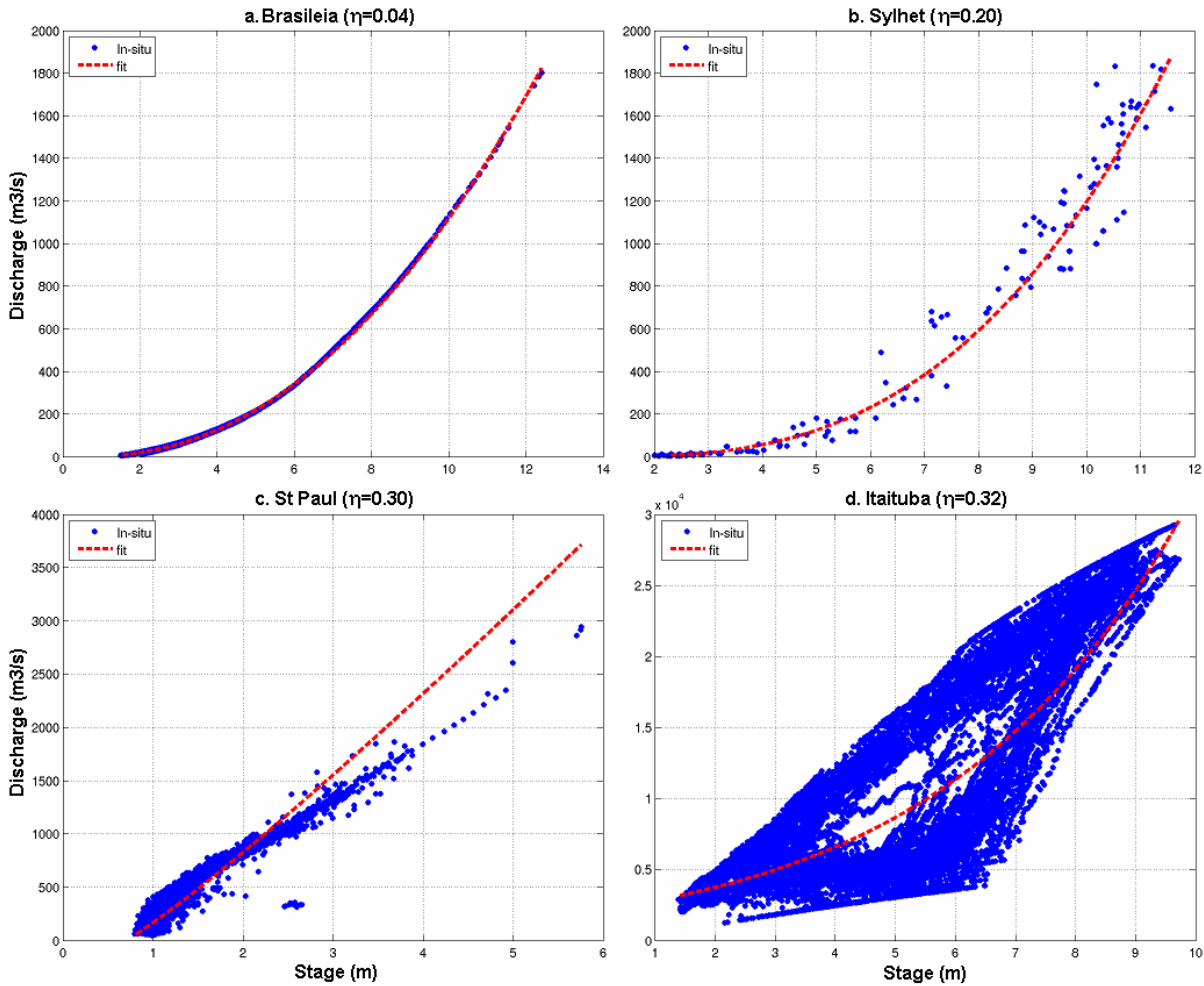

Figure A.3:

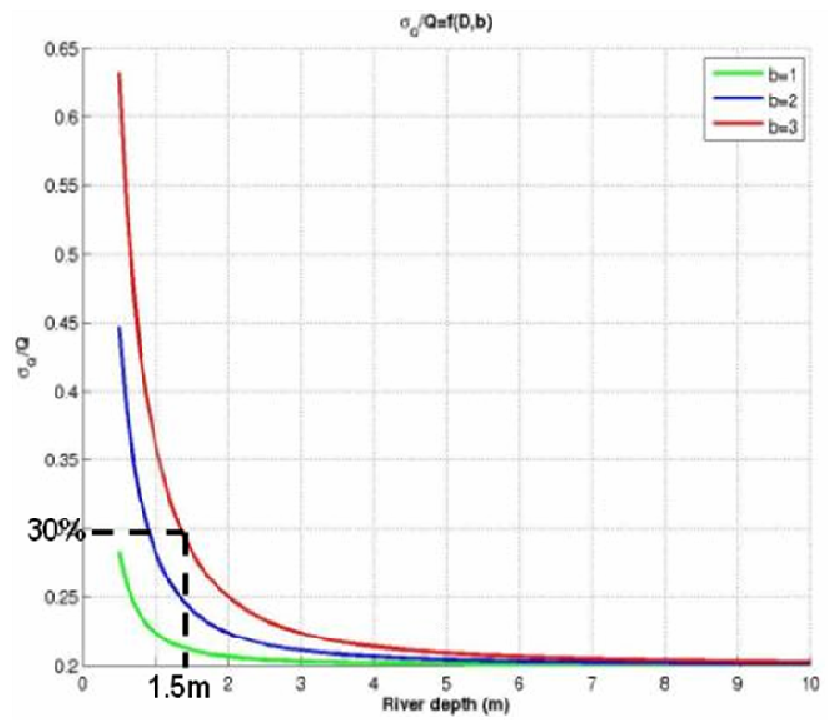


Figure A.4:

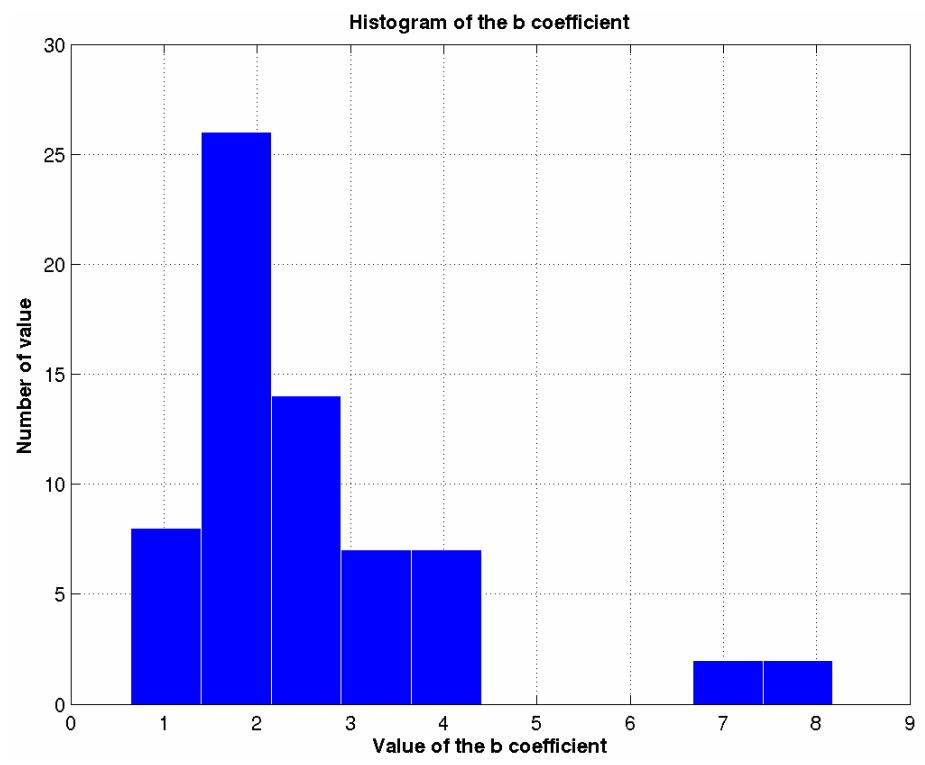

